\title{
State-dependent Energy Allocation in Cod (Gadus Morhua)
}

Christian Jørgensen (Christian.Jorgensen@bio.uib.no)

Øyvind Fiksen (Oyvind.Fiksen@bio.uib.no)

\section{Approved by}

Ulf Dieckmann

Program Leader, ADN

December 2005 Institute, its National Member Organizations, or other organizations supporting the work. 


\section{Contents}

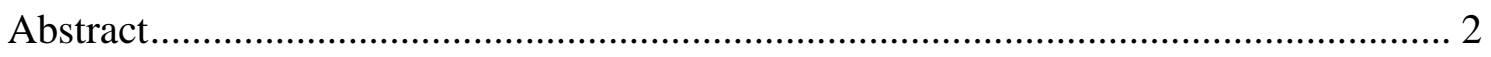

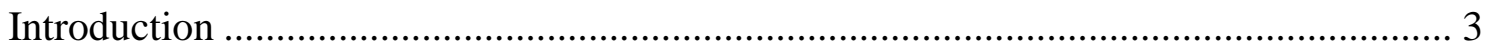

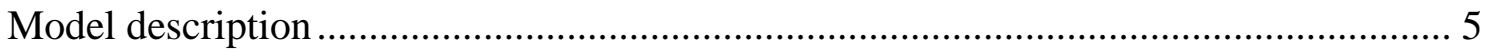

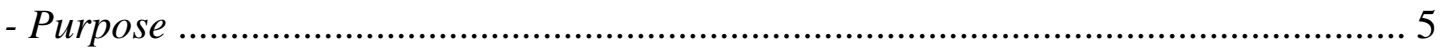

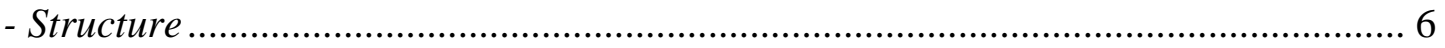

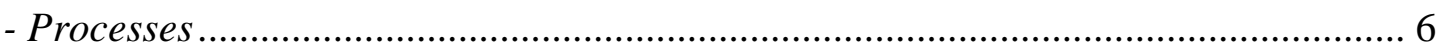

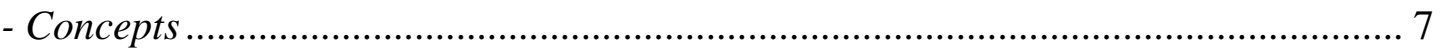

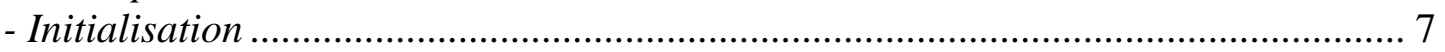

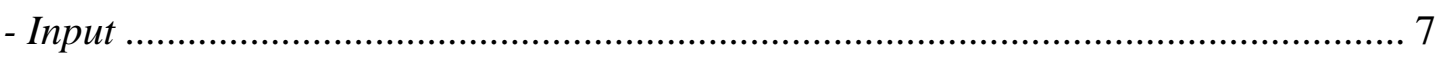

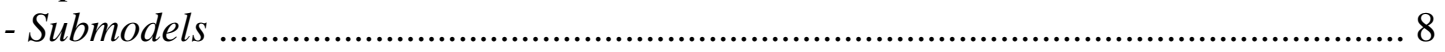

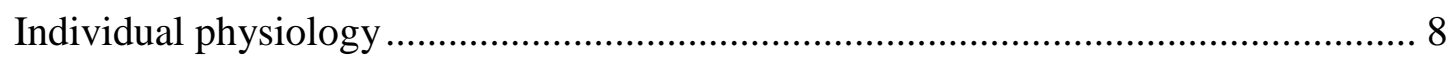

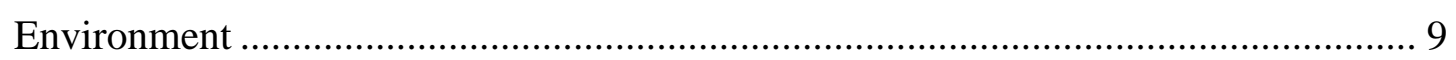

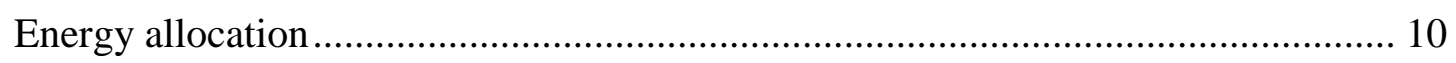

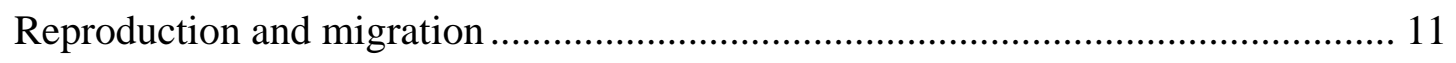

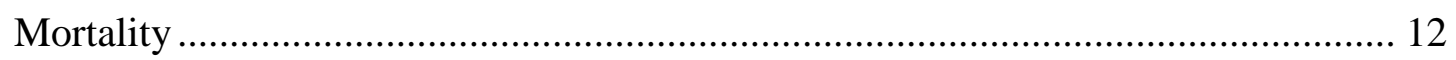

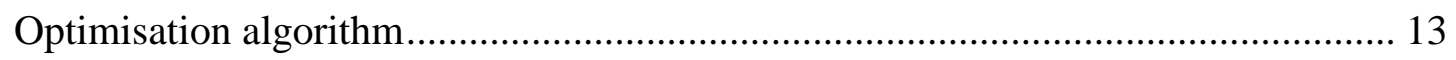

Parameters for the Northeast Arctic cod stock ........................................................... 14

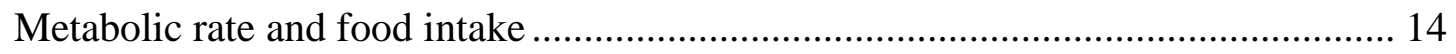

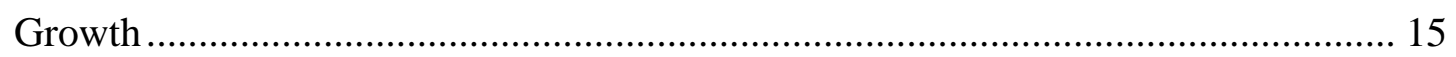

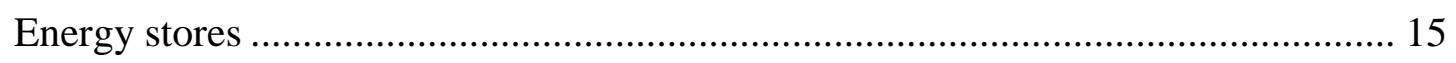

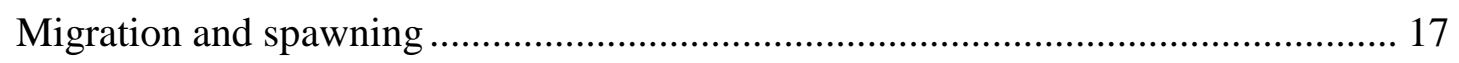

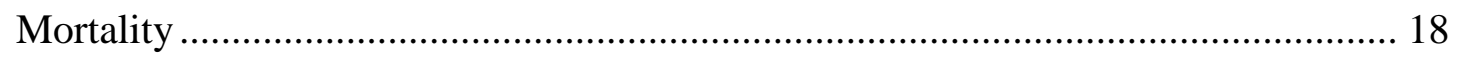

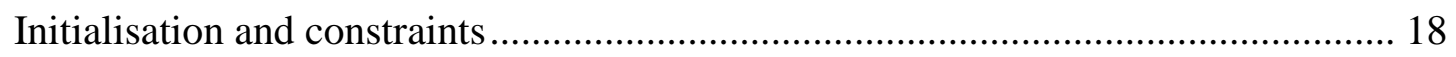

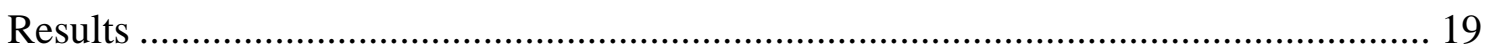

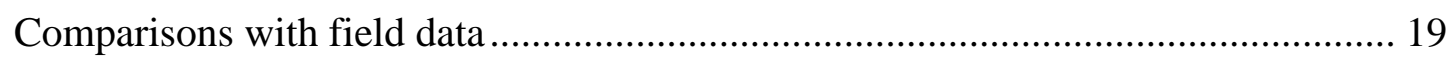

Individual trajectories of growth, allocation, and reproduction ............................... 19

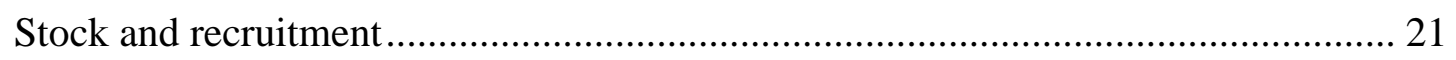

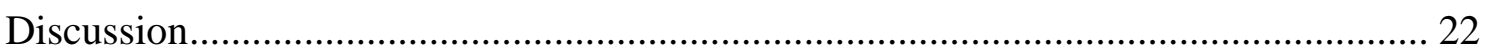

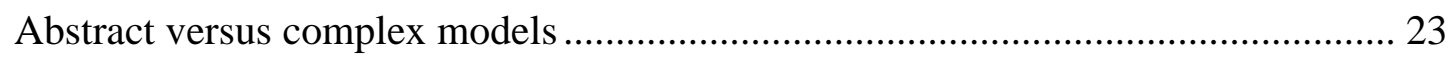




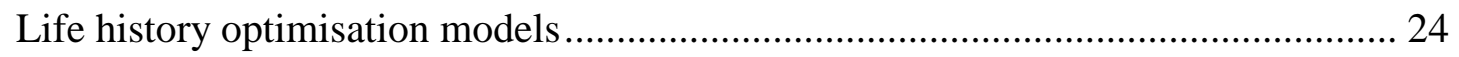

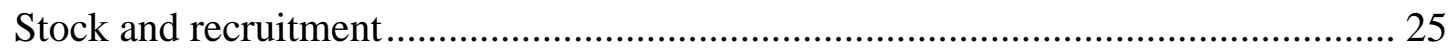

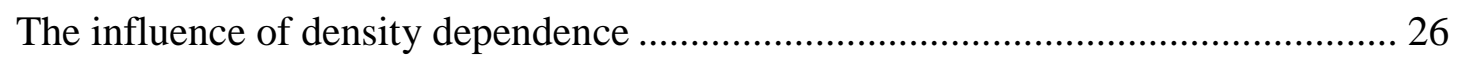

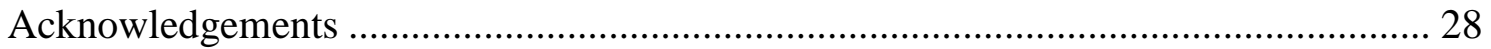

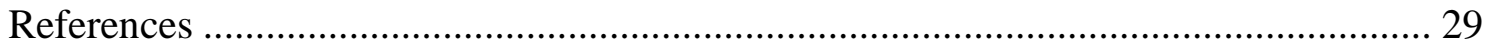

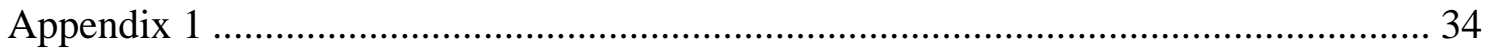

Justification for choice of minimum and maximum condition factors...................... 34

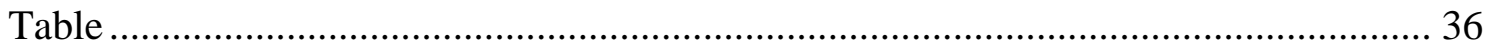

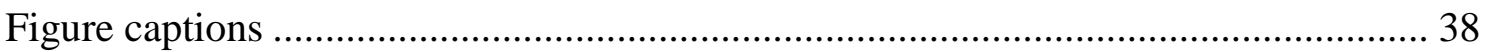

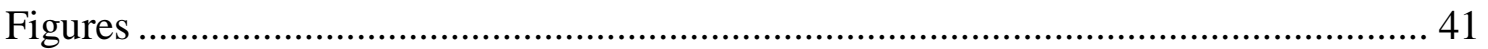




\section{State-dependent energy allocation in cod (Gadus morhua)}




\section{Abstract}

8 Growth and maturation are processes that are tuned to the external environment an

9 individual is likely to experience, where food availability, the mortality regime, and events

10 necessary to complete the life cycle are of special importance. Understanding what influences

11 life history strategies and how changes in life history in turn influence population dynamics

12 and ecological interactions are crucial to our understanding of marine ecology and

13 contemporary anthropogenic induced change. We present a state-dependent model that

14 optimises life-long energy allocation in iteroparous fish. Energy can be allocated to growth or

15 reproduction, and depends in the individual's age, body length, stored energy, and the state of

16 the environment. Allocation and the physiological processes of growth, storing energy, and

17 reproduction are modelled mechanistically. The model is parameterised for Atlantic cod

18 (Gadus morhua); more specifically for the Northeast Arctic cod stock. Growth and maturation

19 predicted by the model fit well with field observations, and based on a further investigation of

20 cod reproduction in the model we conclude that the model has the ability to recapture

21 complex life history phenomena, e.g. indeterminate growth and skipped spawning, and

22 therefore provides an important tool that can improve our understanding of life history

23 strategies in fish.

24 Keywords: Life history evolution, energy allocation, state dependence, dynamic 25 programming, Gadus morhua. 


\section{Introduction}

27 Energy use may be divided into three broad categories - survival, growth, and

28 reproduction. These interests are often conflicting as they are crucial for fitness in different

29 ways. When is an individual predicted to grow to increase future reproduction, and when to

30 reproduce? A large size often means a high reproductive success, but also a low probability of

31 survival until reproduction can finally take place. When is growth predicted to be determinate,

32 and when indeterminate? When is survival probability predicted to influence the optimal adult

33 size? And in the balance between foraging rate and predation risk; when is an individual

34 predicted to hide and when to feed (Krebs and Davies 1993)?

35 For an individual, energy is limited, and these questions represent multiple trade-offs in

36 several dimensions that may be at work simultaneously. Energy allocation - how available

37 energy is diverted towards alternative uses - is the mechanism that integrates the trade-offs

38 through shaping the individual's growth trajectory. This trade-off is the essential core of life

39 history theory (Fisher 1930).

40 Fisheries management is moving towards an ecosystem approach because ecological

41 complexity confounds single-species management. At the same time, human-induced

42 contemporary evolution is identified as the driving force behind observed changes in many

43 marine ecosystems (Stokes and Law 2000; Conover and Munch 2002; Olsen et al. 2004).

44 Because life history theory is an obvious link between ecology and evolution, it provides a

45 tool to predict growth, maturation, and behaviour as ecological forcing changes. Alterations in

46 allocation strategies propagate from individual characteristics via population structure to

47 ecological interactions within and between species. This implies that life history theory

48 should be highly relevant for fisheries science, and understanding the logic of life history

49 theory an integral part of ecosystem management. 
Consider as an example stock-recruitment relationships. Allocation to reproduction earlier

51 or later in life is likely to influence the entire demographic structure and population dynamics.

52 Both mature biomass and the stock's overall egg production will be affected, through changes

53 in maturity-, size-, and fecundity-at-age. Life history theory is, as such, the mechanistic basis

54 for stock-recruitment relationships, and therefore central not only in disentangling stock-

55 recruitment relationships today, but also when making predictions in light of fisheries-induced evolution or climate change.

Intuitively, an old individual should perhaps spend its energy differently from a young one, and being large at a given age harbours different opportunities than being small. Age and body length are likely to influence allocation and should therefore be included as states, i.e.

60 information the individual has about itself and that may influence energy allocation (Houston and McNamara 1999; Clark and Mangel 2000). It is common knowledge that individual condition plays a central role both for growth and reproduction in various fishes (Kjesbu et al. 1991; Burton et al. 1997; Lambert and Dutil 2000). Most organisms in fluctuating environments rely on stores to balance periods when energy is plentiful with periods of energy shortage. Fish and other animals often use lipid stores, either integrated in the muscle tissue (for example clupeids) or in the liver (typical for gadoids). Atlantic cod (Gadus morhua) belongs to the latter category, and the lipid-rich liver constitutes up to $9 \%$ of the body mass among mature fish (Yaragina and Marshall 2000). There is a close relationship between stored energy in the liver and fecundity, and total liver energy in a cod population has been shown to be a good proxy for total egg production (Marshall et al. 1999). Thus

71 individual condition, interpreted as the amount of stored energy, directly affects reproductive success and survival.

Earlier life-history models investigating energy allocation in fish have used a fixed rule to describe lifelong allocation patterns: all available energy was allocated to growth up to a 
variable age at sexual maturation, and a fixed proportion of the energy was diverted to

76 reproduction from then on to maximise reproductive value (Roff 1983; Law and Grey 1989;

77 but see also Strand et al. 2002). These models have provided great insight into life history

78 strategies and the evolutionary dynamics of harvested fish stocks, but time is now ripe to

79 extend the analyses. Here, we investigate state-dependent energy allocation in a

80 physiologically realistic model based on the Atlantic cod. Using four discretised state

81 variables (age, length, stored energy, and food availability), our model allows for

82 approximately 6.4 million independent values to describe a four-dimensional allocation

83 hypersurface. In the strict sense, this is also a fixed rule, but the rule is so complex that it

84 specifies what to do in nearly all situations an individual can encounter throughout life.

85 Our aim is to formulate a flexible life history modelling tool. The high resolution enables

86 seasonal patterns, as well as optimal size-, age-, and condition-dependent life history

87 strategies to emerge, and introduces great flexibility with a sound biological basis into models

88 of fish growth. The model makes very few life-history assumptions, while letting optimisation

89 tools exhibit the best patterns of growth and reproduction. This would also be the growth

90 trajectories supposedly favoured by natural selection, assuming no constraints. We show that

91 the model fits well with field data and experimental work, and that it recaptures much of the

92 ecological dynamics of the Northeast Arctic cod stock. In a companion paper, we apply the

93 same model to analyse skipped spawning behaviour of cod (Jørgensen et al. this issue).

\section{Model description}

$95 \quad$ Purpose

96 We develop a state-dependent model that mechanistically describes energy allocation to

97 growth and reproduction in fish. Since energy is a restricted resource, the life-long pattern in 98 this allocation embodies many of the trade-offs that shape life history. The focus on energy

99 allocation therefore fulfils the purpose of this model, which is to find the optimal life-history 
100 under varying external forcing (e.g., fishing mortality, migration, and food availability).

101 Throughout, we model the energy allocation processes as mechanistically correct as feasible,

102 while retaining flexibility in how allocation can change with time and state. In this way we

103 can use dynamic programming algorithms to find the optimal allocation pattern under the

104 constraints given by the realistic and detailed description of physiology and ecology.

$105 \quad$ Structure

106 The modelling approach in this paper uses dynamic programming to find optimal 107 allocation strategies (Houston and McNamara 1999; Clark and Mangel 2000). The result is a 108 state-dependent energy allocation rule that is a life history strategy. Thereafter, we run 109 population simulations of many individuals following the life history strategy. During these 110 population simulations, age and size distributions emerge and we can assess the implications

111 of the life history strategy on growth, maturation, reproduction etc. The model is 112 parameterised for the Northeast Arctic cod stock, which is a long-lived species with 113 iteroparous reproduction. From their feeding grounds in the Barents Sea, the spawners

114 migrate in spring to the Lofoten area where spawning takes place. The remainder of the year

115 is used for growth and to rebuild energy stores. The time resolution of the model is months

116 (discrete steps), and each month net energy intake is allocated between growth (to increase 117 body size) and reproduction (building energy stores and later gonads). The optimal allocation

118 is found by dynamic programming and depends on four states: age (in months, thus including 119 season); body length (cm); size of energy stores (relative scale); and current feeding 120 conditions. In the model, we consider only female cod.

$121 \quad$ Processes

122 Energy allocated to growth irreversibly increases body length, while stored energy can be 123 used for spawning (migration and egg production) or for metabolism during times when Figure 1

124 feeding conditions are poor (Fig. 1). Density-dependence is not included in the model. 
126 Optimal energy allocation is determined for each state combination with expected 127 reproductive value as fitness measure. The result is a highly flexible multi-dimensional 128 hypersurface that defines a life-history strategy, described by 6.4 million independent points 129 (each point corresponding to a particular combination of the four states). Because rewarding 130 analyses are virtually impossible on such amounts of data directly, we simulated populations

131 of fish realising such life-history allocation strategies to let age-, size-, and condition132 dependent patterns emerge at the individual and population level. A series of monthly energy

133 allocations results in e.g. a time-series of growth, an age at sexual maturation, reproductive 134 episodes with specific fecundities, and skipped spawning seasons (analysed separately in 135 Jørgensen et al. this issue). There is no interaction between individuals in the simulated 136 population, and individuals only have information about the four individual states. Food 137 availability is auto-correlated in time to allow for more extended periods of 138 advantageous/unfavourable environment. In the forward population simulation, this is 139 modelled as a stochastic process. Since optimal strategies may use the predictive power of an 140 auto-correlated environment to fine-tune allocation strategies (e.g., that a favourable 141 environment is likely to persist for some time), current food availability was included as an 142 extra state.

$143 \quad$ Initialisation

144 Juvenile fish were introduced in the model at age 2 years and body length $25 \mathrm{~cm}$. 145 Maximum age was set to 25 years, and the model was solved for body lengths up to $250 \mathrm{~cm}$ to 146 avoid artificial boundary effects.

$147 \quad$ Input

148 Growth and maturation data from the literature were used to test parameter values and 149 general properties. 
151 Details of the relationships defining the model are given below, followed by specific 152 parameter values chosen to represent the Northeast Arctic cod stock.

\section{Individual physiology}

154 Body mass is divided into two compartments: soma and energy stores. Soma $W_{\text {soma }}(L)(\mathrm{g}$ 155 wet weight) includes systematic structures such as skeleton, internal organs, the neural 156 system, a minimum amount of muscle mass, and for which growth is irreversible. Additional 157 energy may be stored above this level for reproduction or to enhance survival during periods 158 of food shortage. Because weight usually increases with length with an exponent slightly 159 above 3, the length-specific somatic weight (with no energy stores) can be written as function 160 of $W \propto L^{3+\varepsilon}$ where $\varepsilon$ for many species falls between 0.1 and 0.4 (Ware 1978):

$$
\text { (Eq. 1) } \quad W_{\text {soma }}(L)=\frac{K_{\min } \cdot L^{3+\varepsilon}}{100 \cdot L_{\text {std }}^{\varepsilon}} \text {, }
$$

where $K_{\min }$ is the minimum Fulton's condition factor $K=W \cdot 100 \cdot L^{-3}$, where weight is measured in $\mathrm{g}$ wet weight and length in $\mathrm{cm}$ (the resulting number varies around 1.0 and

164 describes the fatness or body condition of an individual). For a given length, $K_{\min }$ represents

165 the minimum body mass required for structures; death by starvation can be incorporated to 166 occur at $K_{\min }$ or with increasing probability as $K_{\min }$ is approached. Similarly, there is a limit 167 for how spherical the shape of an individual can be, and $K_{\max }$ is the maximum Fulton's 168 condition factor that includes $W_{\text {soma }}$ and full energy stores. This maximum reflects the 169 physical limitations imposed by anatomy and the need to maintain other body functions while 170 carrying stores, and in this model stores cannot be increased above the level set by $K_{\max }$. For $171 \varepsilon \neq 0, K_{\min }$ and $K_{\max }$ must be specified for a given length $L_{\mathrm{std}}(\mathrm{cm})$. 
172 Energy is normally stored partly as proteins by increasing muscle mass, and partly as lipids

173 either embedded in the muscles (common for salmonids) or stored separately in the liver

174 (typical for gadoids). The average energy density of these energy stores combined, $\rho_{\mathrm{E}}\left(\mathrm{J} \cdot \mathrm{g}^{-1}\right)$,

175 has to be known. We assume that this density is constant, meaning that muscle proteins and

176 lipids are stored at a constant ratio above the minimum muscle mass included in $W_{\text {soma. }}$. When 177 the amount of stored energy $E(\mathrm{~J})$ is known, total body mass $W$ (g wet weight) can be 178 calculated as:

179

(Eq. 2a) $\quad W(L, E)=W_{\text {soma }}(L)+\frac{E}{\rho_{\mathrm{E}}}$,

where $E$ has to be less than or equal to the maximum energy that can be stored, $E_{\max }(\mathrm{J})$ :

181

(Eq. 2b) $\quad E_{\max }(L)=\left(K_{\max }-K_{\min }\right) \cdot \frac{\rho_{\mathrm{E}} \cdot L^{3+\varepsilon}}{100 \cdot L_{\mathrm{std}}^{\varepsilon}}$

182 Energy expenditure is calculated according to the bioenergetics model by Hewett and 183 Johnson (1992). Metabolic rate $\left(M R ; \mathrm{J} \cdot \mathrm{t}^{-1}\right)$ is the product of the standard metabolic rate (SMR; $\left.184 \mathrm{~J} \cdot \mathrm{t}^{-1}\right)$ and an activity parameter $A c t_{\mathrm{Std}}$ to include a routine level of activity:

185

$$
\text { (Eq. 3) } \quad M R=S M R \cdot A c t_{\mathrm{Std}}=\kappa_{1} \cdot W(L, E)^{\beta_{1}} \cdot A_{c t} t_{\mathrm{Std}}, \quad A c t_{\mathrm{Std}}>1
$$

186 Here, $\kappa_{1}\left(\mathrm{~J} \cdot \mathrm{g}^{-\beta_{1}} \cdot \mathrm{t}^{-1}\right)$ is the coefficient and $\beta_{1}$ mass exponent of the allometric function.

\section{Environment}

Food intake $\phi\left(\mathrm{J} \cdot \mathrm{t}^{-1}\right)$ is determined by food availability in the environment and a measure of body size (body mass $W(\mathrm{~g})$ or body length $L(\mathrm{~cm})$ ). A stochastic function $\chi$ and seasonal 
190 cycles $C(t)$ can be incorporated to account for environmental variability in food availability.

191 Feeding intake would thus be

192

(Eq. 4a) $\quad \phi(W)=\chi \cdot C(t) \cdot \kappa_{2} \cdot W(L, E)^{\beta_{2}}$, or

193

(Eq. 4b) $\quad \phi(L)=\chi \cdot C(t) \cdot \kappa_{3} \cdot L^{\beta_{3}}$.

where $\kappa_{2} \cdot W(L, E)^{\beta_{2}}$ and $\kappa_{3} \cdot L^{\beta_{3}}$ are average food intake for a given body mass or body

195 length, respectively. Typical values for the allometric exponents in fish are $\beta_{2} \sim 0.8$ and $196 \quad \beta_{3} \sim 2.5$ (Schmidt-Nielsen 1984).

\section{Energy allocation}

For every time-step, a proportion $u(a, L, E, \phi)$ of net energy intake will be allocated to storage. The variable $u$ is the core of this model, and when optimised over the entire life span

200 it represents optimal life history strategies. As such, $u$ balances the trade-off between growth

201 and reproduction, and as such also integrates the effects of natural and fishing mortalities and

202 the environment. Given $u$, the new state value of the energy stores in the next time-step is

$$
\text { (Eq. 5) } \quad E(t+1 \mid u)=E(t)+u \cdot(\phi-M R) \cdot \delta_{\text {store }}, \quad E \leq E_{\max } .
$$

Here, $\delta_{\text {store }}$ is the assimilation efficiency for the conversion of ingested energy to stores.

205 The concept of the metabolic rate and the relationship between stored energy and spawned 206 eggs embody energy losses at later steps; therefore this value is commonly higher than the

207 assimilation efficiency for growth of somatic structures $\left(\delta_{\text {growth }}\right)$ below. The proportion $(1-u)$ 208 is allocated to somatic growth to a new length $L(t+1 \mid u)$ 
(Eq. 6) $L(t+1 \mid u)=\left[L(t)^{3+\varepsilon}+\frac{(1-u) \cdot(\phi-M R) \cdot \delta_{\text {growth }} \cdot 100 \cdot L_{\text {std }}^{\varepsilon}}{K_{\min } \cdot \rho_{\mathrm{s}}}\right]^{\frac{1}{3+\varepsilon}}$,

$$
L(t+1)-L(t) \leq \Delta L_{\max }
$$

211 where $\delta_{\text {growth }}$ is the efficiency with which available energy is assimilated into somatic

212 structures, and $\rho_{\mathrm{S}}\left(\mathrm{J} \cdot \mathrm{g}^{-1}\right)$ is the energy density of somatic tissues and typically lower than the

213 energy density of stores. The equation basically states that growth is allometric with the

214 exponent $(3+\varepsilon)$, and new tissue is laid down according to available food, assimilation

215 efficiency and the energy density of somatic tissue. The constraint on maximum theoretical

216 growth rate, $\Delta L_{\max }\left(\mathrm{cm} \cdot \mathrm{t}^{-1}\right)$, acts as an upper physiological limit for length increment per time

217 and can be parameterized from growth studies in food-unlimited immature fish.

\section{Reproduction and migration}

219 Feeding behaviour may be altered during reproduction and possibly also during the 220 migration to and from the spawning grounds. Therefore, the duration of these events must be 221 explicitly incorporated into the time-structure of the model. The time required for the 222 migration $T_{\mathrm{M}}(t)$ is the migration distance $D_{\mathrm{M}}(\mathrm{m})$ divided by the swimming speed through the 223 water masses:

224

$$
\text { (Eq. 7) } \quad T_{\mathrm{M}}=\frac{D_{\mathrm{M}}}{\left(U_{\mathrm{S}}+U_{\mathrm{C}}\right)} \text {, }
$$

where $U_{\mathrm{S}}\left(\mathrm{m} \cdot \mathrm{t}^{-1}\right)$ is the average or typical swimming speed during the migration and $U_{\mathrm{C}}$

$226\left(\mathrm{~m} \cdot \mathrm{t}^{-1}\right)$ the speed of possible currents that have to be taken into consideration. If $U_{\mathrm{C}} \neq 0$ or the migration route differs to and from the spawning grounds, $T_{\mathrm{M}}$ and the energetic cost of 
migration $E_{M}(J)$ have to be calculated separately for each direction. For species migrating in groups or schools, $U_{\mathrm{S}}$ will often be identical for smaller and larger individuals.

230 The energetic costs of migration $E_{M}(J)$ can then be found from:

$$
\text { (Eq. 8) } \quad E_{\mathrm{M}}(W, L)=\operatorname{SMR}(W) \cdot\left[\left(\frac{\kappa_{4} \cdot U_{\mathrm{S}}^{1.5}}{L}+1\right)-A c t_{\mathrm{std}}\right] \cdot T_{\mathrm{M}}, \quad E_{\mathrm{M}} \geq 0
$$

The expression $\left(\kappa_{4} \cdot U_{\mathrm{S}}^{1.5} \cdot L^{-1}+1\right)$ determines an activity parameter similar to $A c t_{\text {std }}$ from

233 swimming speed and body size. Other formulations can be used, but a function on this form 234 proved to capture the dynamics of both body length and swimming speed in empirical data for 235 Atlantic cod (Strand et al. 2005) and other fish species (Nøttestad et al. 1999).

236 Stored energy is eventually spawned, and total egg production $b$ is proportional to invested 237 energy (Marshall et al. 1999). If migration takes place, energy to fuel migration from 238 spawning grounds back to feeding areas has to be retained, although this constraint may be 239 modified to allow for semelparous life history strategies.

$$
\text { (Eq. 9) } \quad b(E)=\kappa_{5} \cdot\left(E-E_{\mathrm{M}}\right) \text {. }
$$

\section{$241 \quad$ Mortality}

A flexible mortality regime incorporating length-, size-, or age-specific natural mortality $M$, size- or stage-selective fisheries mortality $F$ and additional mortality during migration and

244 spawning $M_{\mathrm{S}}$ can be specified. Mortality rates $\left(\mathrm{t}^{-1}\right)$ are summed and survival probability $S$ over a discrete time interval $T(\mathrm{t})$ is then given by:

(Eq. 10) $\quad S=e^{-T\left(M+F+M_{\mathrm{S}}\right)}$ 
If death by starvation is included, the above equation will apply for $E>0$, while $S=0$ when $E \leq 0$. Details of the mortality regime used for calculations in this paper are given below under the heading Parameters for the Northeast Arctic cod stock.

\section{Optimisation algorithm}

Optimal life-history strategies were optimized using dynamic programming (Houston and McNamara 1999; Clark and Mangel 2000). Models of this type optimise a fitness function by backward iteration through an individual's life history, starting at the maximum age and constantly assuming that the individual acts optimally at every decision point in its future life. A central point is that such models separate between the information available to the individual (here its states) although other factors may affect its success (for instance the development in food availability). Dynamic programming then finds the best response, conditional on the information known by the individual, and averaged over possible outcomes. The optimisation problem considered here is thus to find the allocation to reproduction $u(a, L, E, \phi)$ that maximises future expected reproductive value $V(a, L, E, \phi)$

261 discounted by survival probability $S$ for every combination of the four states (age $a$, body

262 length $L$, energy store $E$, and environment $\phi)$ :

$V(a, L, E, \phi)=\max _{u}\left\{S \cdot \sum^{\phi(t+1)} P(\phi(t+1) \mid \phi(t)) \cdot[V(a+1, L(t+1 \mid u), E(t+1 \mid u), \phi(t+1)]+b(E)\}\right.$

Here $P(\phi(t+1) \mid \phi(t))$ is the conditional probability of food availability in the next time step

266 given food availability in this time step. To find mean expected fitness one has to take the

267 sum over all possible states of food availability at time $t+1$. During the spawning season, 268 fitness values for both migrating and non-migrating individuals were calculated, and the 
269 option yielding the highest fitness value was stored.

270

271

272

273

274

275

276

278

279

280

281

282

283

284

\section{Parameters for the Northeast Arctic cod stock}

The parameters below are selected to describe the physiology and ecology of the Northeast Arctic cod stock (summarised in Tab. 1). The time resolution is months to allow for seasonal variations in allocation patterns.

\section{Metabolic rate and food intake}

The equations for metabolic rate have been parameterised for Atlantic cod by Hansson et al. (1996). At an ambient temperature of $5{ }^{\circ} \mathrm{C}$, and with a standard activity level set to Act $_{\text {Std }}=1.25$ (Hansson et al. 1996), monthly metabolic rate MR $\left(\mathrm{J} \cdot \mathrm{month}^{-1}\right)$ was:

(Eq. 12) $\quad M R=S M R \cdot A c t_{\mathrm{Std}}=2116 \cdot W(t)^{0.828}$,

where SMR is the standard monthly metabolic rate $\left(\mathrm{J} \cdot \mathrm{month}^{-1}\right)$.

Food intake at $5^{\circ} \mathrm{C}$ was calculated according to Jobling (1988):

(Eq. 13a) $\phi(L)=\chi(t) \cdot 276 \cdot L^{2.408}$,

by introducing additional stochasticity of the environment $\chi(t)$, auto-correlated in time and given by:

(Eq. 13b) $\chi(t)=\bar{\chi}+C_{1} \cdot(\chi(t-1)-\bar{\chi})+C_{2} \cdot N \cdot \sqrt{1-C_{1}^{2}}$,

where $N$ is a random number drawn from a standard normal distribution $N(0,1), C_{1}=0.9$ is the auto-correlation coefficient, $C_{2}=0.15$ scales the variance, and $\bar{\chi}=0.75$ is the mean of the 
287 stochastic distribution. The feeding equation 13a was obtained in farmed cod fed to satiation 288 (Jobling 1988) and $\bar{\chi}=1$ would correspond to the same feeding level in the model; by setting $289 \bar{\chi}=0.75$ the mean feeding intake in the model is $25 \%$ less than for the farmed cod. Cod 290 utilise many different prey species and can switch during unfavourable periods; there is also a

291 maximum feeding rate that sets an upper limit for energy intake; for these reasons $\chi(t)$ was

292 constrained to fall between 0.3 and 1.5.

\section{Growth}

We used $\varepsilon=0.065$, which was found from a log-log regression between mean length and weight for Northeast Arctic cod age-classes 1-12 measured in the field over the period 19782000 (ICES 2003). Maximum and minimum condition factors were set to $K_{\min }=0.75$ and

$297 K_{\max }=1.25$ for a standard length of $L_{\mathrm{std}}=70 \mathrm{~cm}$; see Appendix 1 for justification. Maximum

298 length increment was set to $\Delta L_{\max }=18 \mathrm{~cm} \cdot \mathrm{year}^{-1}$ and is a constant independent of length in 299 this model, since field and experimental data show that length-growth is typically linear with 300 time for food-unlimited immature cod, and decreases thereafter as a result of allocation to 301 reproduction (e.g. Jørgensen 1992; Michalsen et al. 1998).

\section{$302 \quad$ Energy stores}

303 Together, muscle and liver stores vary between $K_{\min }$ and $K_{\max }$, and the average energy 304 density of full stores can be calculated provided that we know the energy content and relative 305 contribution of each tissue type. Lipids are stored primarily in the liver, and the liver 306 condition index $(L C I)$ is liver weight expressed as percentage of total body mass. $L C I$ reaches 307 maximum values just prior to spawning; maximum monthly mean values for the Northeast 308 Arctic cod stock are typically $7-8 \%$ in early winter if food is abundant (Yaragina and 309 Marshall 2000). A maximum value that can be obtained by the most successful individuals 310 may exceed the average and was therefore set to $L C I_{\max }=9 \%$. Total liver energy density 


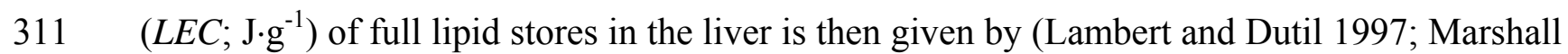
312 et al. 1999):

(Eq. 14) $\quad L E C=2.477 \cdot 10^{4} \cdot\left(1-e^{-0.52\left(L C I_{\max }-0.48\right)}\right)$.

The remainder of the weight increase due to storage is increased white muscle mass, which

315 has an energy density of $4130 \mathrm{~J} \cdot \mathrm{g}^{-1}$ (Holdway and Beamish 1984, their table V). The average 316 energy density of full stores can then be calculated to be $\rho_{\mathrm{E}}=8700 \mathrm{~J} \cdot \mathrm{g}^{-1}$. For comparison, 317 whole body energy density, which includes all tissue types and not only the lipid-rich energy 318 stores, peaked at $7000 \mathrm{~J} \cdot \mathrm{g}^{-1}$ in a study of the chemical composition of cod (Holdway and 319 Beamish 1984). The energy density of somatic tissues was furthermore calculated to 320 be $\rho_{\mathrm{S}}=4000 \mathrm{~J} \cdot \mathrm{g}^{-1}$ from whole body energy content minus the liver for cod reared at $5{ }^{\circ} \mathrm{C}$ in a 321 study on chemical composition analysis of Atlantic cod (Holdway and Beamish 1984, their tables II, III and VI).

323 It is difficult to estimate energy loss in metabolic reactions, especially when the ingested 324 molecules are only moderately rearranged before e.g. becoming part of the animal's stores. In 325 general, half the energy in food can be made available as ATP (adenosine triphosphate), and 326 maximum muscle efficiency (energy in ATP versus physical work done) is around 0.45 327 (Alexander 2003), but we have not been able to find more exact determinations of overall 328 metabolic pathways of relevance to this model. We set the proportion of ingested energy that 329 was preserved when stored to $\delta_{\text {store }}=0.4$. This value is relatively high because lipid and 330 protein storage requires few biochemical rearrangements compared to somatic growth 331 processes, and $\delta_{\text {store }}$ accounts only for energy lost from ingestion to storage; energy losses 332 during metabolism and production of eggs is taken into account in the empirical relationships 333 in eqs. 9 and 12. Assuming further that the efficiency in converting energy from stores to eggs 
334 is also 0.4 , and that growing somatic structures such as bones and neural tissue is only half as

335 efficient as the entire process from ingestion to egg production, we ended up with

$336 \delta_{\text {growth }}=0.08$ of the energy being preserved when used for somatic growth. These parameters

337 were chosen also based on predicted growth patterns in terms of length and weight in the

338 model.

\section{Migration and spawning}

340 Each January fish can either start migration in order to spawn, which occupies January

341 through May, or stay at the feeding grounds. Atlantic cod eat little or nothing during the

342 spawning season (Fordham and Trippel 1999). This has been simplified in the model, where

343 there is no net gain in energy for spawning fish $\left(\phi(W)=S M R \cdot A c t_{S t d}\right)$. For calculations of 344 energy consumption during spawning migrations, we used $\kappa_{4}=320 \mathrm{~cm} \cdot \mathrm{s}^{1.5} \cdot \mathrm{m}^{-1.5}$ (Strand et al. 345 2005), $U_{\mathrm{S}}=0.3 \mathrm{~m} \cdot \mathrm{s}^{-1}$ (Brander 1994), and $U_{\mathrm{C}}=0.1 \mathrm{~m} \cdot \mathrm{s}^{-1}$ (Brander 1994). Because the current

346 flows north along the Norwegian coast, $\left(U_{\mathrm{S}}+U_{\mathrm{C}}\right)$ was used for estimating required time for

347 the southward migration, while $\left(U_{\mathrm{S}}-U_{\mathrm{C}}\right)$ was used for the migration north. The migration 348 distance $D_{\mathrm{M}}=7.8 \cdot 10^{5} \mathrm{~m}$ was measured on a nautical map. The required energy for migration 349 was subtracted from the balance in one month, although the migration may take longer.

350 Stored energy was, for simplicity, spawned in one batch in March. Although there are 351 indications that cod may adjust their spawning intensity between years to compensate for 352 previous reproductive investments (Kjesbu et al. 1996), all stored energy except that required 353 for the northbound migration was used for egg production in this model. Introducing a 354 variable spawning intensity would mean to include one more trait in the model; deemed too 355 complicated at present it suggests a potential direction in the future. In eq. $9, \kappa_{5}$ was set to $356 \quad 0.407 \cdot P_{\text {lipids }}$ (Marshall et al. 1999), where $P_{\text {lipids }}=0.63$ is the proportion of total energy stored 357 that is stored as lipids in the liver and can be derived from the considerations on energy 358 densities in different tissues above. 


\section{Mortality}

360 Growth and maturation in the model are very sensitive to the choice of mortality regime.

361 The mortalities in the spawner and the feeder fisheries were chosen to lie between the historic

362 situation (before the onset of trawling), and the current harvesting regime. In evolutionary

363 terms, this would imply that the resulting life history is partly adapted to the new and higher

364 fisheries mortalities (either through contemporary evolution or through phenotypic plasticity

365 that has evolved in response to variable mortality patterns in the past). The simulations in this

366 paper used the following mortalities (all rates per year): natural mortality $M=0.25$, increased

367 mortality during the spawning/migration period $M_{\mathrm{S}}=0.1$, spawner fisheries mortality

$368 F_{\mathrm{S}}=0.22$, and feeder fisheries mortality $F_{\mathrm{F}}=0.20$. The spawning season lasts five months in

369 this model, so annual mortality rates affecting only spawning individuals was spread evenly

370 over these five months. The probability of surviving the next month was thus

$371 S=e^{-\left[M / 12+\left(M_{\mathrm{S}}+F_{\mathrm{S}}\right) / 5\right]}$ when at the spawning grounds and $S=e^{-\left(M+F_{\mathrm{F}}\right) / 12}$ when in the Barents

372 Sea (from Eq. 10). The sensitivity to and effects of different mortality regimes are analysed

373 together with skipped spawning in a companion paper (Jørgensen et al. this issue). We have

374 not specified any size-dependent mortality.

Initialisation and constraints

The model starts from cod age 2, at which individuals were initiated with a length $L_{\min }=25 \mathrm{~cm}$ (Helle et al. 2002) and 30\% energy stores in the forward simulation model.

378 Maximum length had to be defined for the dynamic programming and was set to $L_{\max }=250$

379 cm (Brander 1994; Svåsand et al. 1996); this is only a technical limit that has to be well above

380 maximum lengths observed in cod to avoid boundary effects. The model does not incorporate

381 age-specific rates of mortality (i.e. aging) apart from a maximum age of 25 years.

Table 1

382 Many of the parameter values above can be used for other cod stocks. Mortalities and

383 details regarding the spawning migration vary between stocks and have to be changed. The 
384 physiology remains the same, except for the temperature dependence of food intake (Jobling 385 1988) and metabolic rate (Hansson et al. 1996).

$386 \quad$ Results

\section{Comparisons with field data}

388 We illustrate how growth in the model compares with field data from the Barents Sea and 389 the Lofoten area for the period 1978-2000 (Fig. 2; ICES 2003). To obtain the model's 390 prediction of growth, a life history strategy was first found by optimisation using a 391 representative set of parameters including natural and fisheries mortalities. The life history 392 strategy was then simulated in an artificial population where population dynamics as well as 393 patterns of growth and reproduction emerge. The desired individual and stock properties were recorded from the simulation; in this case weight- and length-at-age. For all ages, mean weight- and length-at-age predicted by the model fall within the range of observed mean weight- and length-at-age from field data, and there is no systematic bias.

The model also predicted the proportion of the stock that would be mature-at-length and age (Fig. 3a and 3b, respectively). Mean length at 50\% maturation was $78 \mathrm{~cm}$ and the corresponding age 7.5 years. For comparison, field data on the proportion mature-at-age from

400 Lofoten and the Barents Sea combined (ICES 2003, their table 3.5) is also shown (Fig. 3b) 401 and does not deviate notably from the model's predictions. The correspondence between the 402 model and field data in terms of growth and reproduction forms the basis for further 403 comparisons between the model and the Northeast Arctic cod stock.

\section{Individual trajectories of growth, allocation, and reproduction}

405 We provide a more detailed picture of how allocation between growth and reproduction 406 shapes the life history of cod, by showing growth trajectories in terms of length- and weight407 at-age, energy allocation, condition, food availability, survival probability, and the temporal 
pattern of reproduction for one particular individual cod (Fig. 4). As immature, this individual

409 prioritised growth, and length growth was almost linear with time (Fig. 4a). Allocation to stores was low, and only minor energy reserves were kept to balance the risk of starvation

411 (Figs. 4b-c). In anticipation of reproduction, allocation shifted from growth to stores at age 7,

412 approximately one year prior to the first spawning migration (Fig. 4b). The energy stored

413 during this period prior to reproduction is later used for spawning migration and gonad

414 development. As a consequence of increased allocation to stores, length growth slowed down

415 and the condition factor increased rapidly. Egg production during the spawning season is also

416 shown (Fig. 4d). Repeated reproductive events lead to similar patterns throughout the

417 individual's life-time: allocation to stores prior to reproduction, rapid weight increase and no

418 length growth, followed by reproduction. Curiously, this cod invested all its energy in growth

419 also in some of the years after sexual maturation (e.g., at age 9 and partially at age 13), and

420 skipped spawning entirely in those years. The phenomenon of skipped reproduction is studied

421 more closely in Jørgensen et al. (this issue). Food availability (Fig. 4e) also influenced growth

422 and reproduction. The variable food availability this cod experienced while immature lead to

423 concomitant variations in growth rate (visible in Fig. 4a). Poor food availability also

424 coincided with skipped spawning at age 13 and age 19. Survival probability until a given age

425 dropped faster when at the spawning grounds since the combined mortality from fishing and

426 reproduction is higher than the fishing mortality at the feeding grounds (Fig. 4f; note the

427 logarithmic axis).

428 Fecundity will vary with the individual's size, its stored energy, and the size-dependent 429 energetic cost of migration. Some relations with fecundity are shown to visualise these effects 430 (Fig. 5). Maximum and average fecundity were increasing with age, but older individuals

431 were also showing a higher variance (Fig. 5a). This is due to two reasons. First, a higher age 432 will per se reduce the importance of growth and will tend to favour reproduction. Because of 
433 the terminal age in the model, the expected future lifespan is lower at higher ages. This

434 reduces the value of the future component of reproduction relative to the present, meaning 435 that energy would best be used for reproduction. In economic terms, reproduction is low-risk 436 instantaneous liquidation of available capital (stored energy), while growth is an investment in

437 the future, subjected to a pay-off that is becoming increasingly more risky with higher age (or, 438 in terms of the strategy, the devaluation rate is increasing with senescence). Second, older 439 individuals are usually larger and will thus spend relatively less energy for the migration. This 440 gives them more leeway than smaller fish, and while small fish were forced to have full 441 energy stores to spawn, spawning fish of larger size would show higher variance in their 442 stored energy.

443 The relationship between weight and fecundity was also highly variable (Fig. 5b), although 444 less so for small fish (up to $7 \mathrm{~kg}$ ) and for the very few large fish that were realised in the 445 simulated population. The same trend was visible for the relationship between fecundity and 446 length (Fig. 5c). It thus seems that age, weight, and length are all poor predictors of fecundity 447 when used alone. Liver weight turned out to be a better predictor of individual fecundity (Fig. $4485 \mathrm{~d})$. The variance around this relationship was highest when liver weight was low, because 449 small individuals with lipid-rich livers and a starved larger individual can have the same liver 450 weight. In the model, liver energy content is the proximate mechanism that determines egg 451 production; the variance around the relationships results because individuals in the population 452 differ in age, size and stored energy (Fig. 5a-d).

\section{Stock and recruitment}

454 The picture looked somewhat different for egg production at the population level (Fig. 6), 455 since variation at the individual level may cancel out or become amplified by correlations 456 between individual states in the population. Variance was highest when plotted against total 457 biomass of all sexually mature individuals (coefficient of variation for linear regression 
$458 \quad r^{2}=0.897$; Fig. 6a). Removing sexually mature individuals that did not engage in spawning

459 removed a lot of the variance (Fig. $6 \mathrm{~b} ; r^{2}=0.995$ ). Liver weight was an even better predictor

460 of egg production at the population level compared to its predictive ability for individual cod

461 (Fig. 6c; $r^{2}=0.986$ ). When the population's total egg production was plotted against total

462 liver weight of only the individuals that were actually spawning, the points fell more or less

463 onto a straight line (Fig. $\left.6 \mathrm{~d} ; r^{2}=0.998\right)$.

$464 \quad$ Maturity and fecundity relationships were also influenced by past food availability (Fig. 7;

465 all values were from January, just prior to the spawning migration in the simulations). As

466 predictor of mature biomass (defined as all fish that spawned for the first time this year or had Figure 7

467 spawned previously), the tightest relationship was obtained by averaging food availability

468 over the last two years (Fig. 7a). For the stock's total egg production, the best relationship

469 was obtained when mean food availability was averaged over the last year (Fig. 7b). The

470 difference in time scales between these two relationships reflect that building gonads is a

471 faster process than increasing mature biomass, which relies on both maturation and growth.

\section{Discussion}

473 We present here a model for energy allocation, parameterised for the Northeast Arctic cod.

474 Since ingested energy can only be used once, the allocation pattern integrates trade-offs

475 between life-history components and environmental factors and result in individual growth

476 trajectories and maturation patterns. The model is complex but realistic. It adequately predicts

477 complex life history phenomena such as indeterminate growth, skipped spawning and

478 variability in age and size at maturation.

479 We make three assumptions: (i) that energy can only be used once; (ii) energy allocation is 480 optimal at every point in life in the sense that it maximises fitness; and (iii) the fitness of an 481 individual is approximated by its expected future reproductive value (true when density 482 dependence acts early in life and the population is in equilibrium, Mylius and Diekmann 
1995). This model makes predictions about life histories from first principles by finding

484 optimal phenotypes. When compared with data, a fit between the predicted life histories and 485 those realised in nature makes it likely that the most important assumptions are built into the 486 optimality model, and that the model turn can be used to formulate or test hypotheses under a 487 variety of ecological conditions (Sutherland 2005). The model provides a level of detail and 488 realism that can readily be compared with field and experimental data, and the fit in terms of 489 both growth and maturation are promising for further comparisons with field observations.

\section{Abstract versus complex models}

491 Models with many parameters, such as the one presented here, are sometimes accused of 492 being overly complex. Models can be complex in many ways, however. Although our model 493 is rich in mathematical and mechanistic detail, it has a low level of abstraction. Abstract 494 assumptions are replaced by a detailed and realistic formulation of energy allocation. We have 495 aimed at parameters with sound biological meaning and included extensive arguments for the 496 choice of parameter values. Species- and stock-specific parameters are required to make 497 predictions about real-world scenarios. The results presented here are quite robust, as the 498 patterns and results reported in this paper and Jørgensen et al. (this issue) are consistent 499 throughout a wide range of parameter combinations.

500 Some of the properties of this model that resemble real-world dynamics, such as 501 indeterminate growth, variation in age and size at maturation, and skipped spawning, do not 502 occur if we switch off for instance the temporal variability in food intake. In a life history 503 model for the Müller's pearlside (Maurolicus muelleri) stochasticity in the environment also

504 lead to bet-hedging strategies and a two-year life cycle in stead of reproduction within one 505 year only (Strand et al. 2002). Environmental variability is inherent in biological systems, and 506 the observation that several real-world phenomena only occur when sufficient stochasticity is 507 part of a model suggests that they are adaptations to a variable environment. Furthermore, 
these adaptations affect population dynamics and ecological interactions. This basic insight is

509 an argument for including stochasticity in models, especially where adaptations are

510 concerned. Much of the rest of the complexity in this model is built around this stochasticity:

511 size has to be included as a state because the variable environment will lead to temporal

512 variations in size-at-age, and storing energy is a means of buffering environmental variation.

\section{$513 \quad$ Life history optimisation models}

514 This model aptly recaptures complex life history phenomena. Optimisation models have 515 traditionally predicted determinate growth, where allocation should shift abruptly from 516 growth to reproduction at a fixed point in life (e.g., Taborsky et al. 2003). The gradually 517 increasing allocation to reproduction, as seen in the decelerating growth for individuals in our 518 model, is common in nature but only rarely reproducible in models (but see Kozlowski and

519 Teriokhin 1999; indeterminate growth is reviewed by Heino and Kaitala 1996). Our model 520 also shows that cod may skip reproduction in some years, and this phenomenon of skipped 521 reproduction has to our knowledge not previously been reproduced in models (Jørgensen et al.

522 this issue). Growth in the model also fits well with observed growth patterns both in terms of 523 length and weight at age when representative parameter values are used. In sum, we feel 524 confident that the model behaves well and predicts reasonable and realistic growth and 525 maturation patterns, and therefore that the results increase our understanding of the evolution 526 of life history strategies in fish.

527 In principle, the model (as is typical for dynamic programming models) does not separate 528 between phenotypic plasticity and evolutionary change - it simply finds the optimal life 529 history strategies for a given set of parameters. The reaction norm concept describes the 530 interaction between gene and environment, and is relevant for maturation processes since a 531 fixed, genetically determined reaction norm can cause maturation to occur over a range of 532 sizes and ages as the environment changes (Stearns and Koella 1986). The concept has been 
533 extended to the probabilistic maturation reaction norm as a method to analyse maturation data

534 (Heino et al. 2002). The rationale behind the reaction norm approach is that size at age, which 535 naturally reflects past growth rate, should mean more for the timing of sexual maturation than

536 size or age alone. Since age and length are states, our model includes the phenotypic plasticity

537 described by the maturation reaction norm concept, and also uses stored energy as an

538 additional dimension to fine-tune maturation dynamics.

\section{Stock and recruitment}

$540 \quad$ Finding promising proxies for recruitment is essential to successful management of our

541 marine fish stocks. The exercise undertaken in this paper is a good illustration of how 542 different proxies behave in a modelled stock where everything is in principle known. 543 Fecundity is modelled strictly mechanistically, and is proportional to the amount of stored 544 energy in the liver (Marshall et al. 1998; Marshall et al. 1999). Even though this is a 545 deterministic relationship with no noise added, various measurable individual characteristics 546 perform rather poorly as predictors of fecundity. The best predictor at the individual level 547 not surprising given the direct link between liver energy stores and fecundity - is liver weight.

548 The strict upper limit in all the graphs showing fecundity is due to a constraint specified in 549 the model: individual condition factor could not exceed $K_{\max }$. The lower limit of fecundity is 550 more variable, and emerges from trade-offs between many factors, e.g., at what combination 551 of age and size should one mature, should one spawn although energy stores are not 552 completely full, would these considerations be modified by the current availability of food 553 etc. These trade-offs can be solved by the life history approach taken in this paper, and the 554 result is that the lower limit of fecundity or total egg production resembles the variance one 555 can see in real data.

556 In nature, similar trade-offs determine the maximum fecundity (i.e., the upper limit). For 557 example, how does a bulging belly influence swimming efficiency or feeding (is there room 
558 for digestion)? Will large gonads impair the functionality of the swim bladder (Ona 1990)? If

559 so, what are the potential consequences? To what degree will activity level at the spawning 560 grounds influence reproductive success? These trade-offs are harder to model because we 561 know less about them.

562 By comparing Figures 5 and 6, it is promising to note that proxies at the population level 563 are better predictors of the stock's total egg production than individual characteristics. In 564 other words, the variable demography of the fish stock removes some of the variation inherent 565 in relationships between individual characteristics and fecundity. A likely explanation for this 566 is that reproduction is normally determined by a few abundant cohorts (e.g., first-, second567 and third-time spawners). Over time, the variability of these cohorts between years is less than

568 the total variation between individuals in the population as a whole, and this will tend to 569 reduce the variance when egg production is plotted as a function of population-level 570 characteristics.

571 At the individual level, liver weight was the best proxy, and this proxy performed well also 572 at the population level. However, excluding the non-spawning part of the population provided 573 even better predictions than using the total liver weight of the mature population. Skipped 574 spawners will contribute to the stock's total liver weight without producing any eggs, and will 575 therefore be the source of much of the variation. This goes for both the mature biomass-egg 576 production relationship, as well as the relationship between total liver weight and egg 577 production. The phenomenon of skipped spawning is studied in greater detail in Jørgensen et 578 al. (this issue), providing an example application of this model to more complex questions of 579 ecology and life history.

\section{The influence of density dependence}

581 With the optimisation technique used in this paper, dynamic programming, it is not 582 straightforward to find optimal life history strategies when a population is regulated by 
583 density dependence (Clark and Mangel 2000; Houston and McNamara 1999). The model can

584 be turned into a dynamic game, but this would require a much more complex model

585 (McNamara et al. 1997). Simulations of population dynamics, however, require that some

586 regulatory mechanism controls population abundance, otherwise the population would go

587 extinct or grow exponentially and infinitely. As a consequence, life history allocation

588 strategies are found by optimisation without density dependence in this model, and the

589 strategy thereafter simulated in a population where density dependence acts on juvenile

590 survival. Before we can compare predictions from this model with results from density-

591 dependent optimisation, we cannot with certainty conclude what the effects of density

592 dependence are. The fit between the model's predictions and field data suggests that the

593 model recaptures much of the ecological realism for this stock, even without adaptation to

594 density dependence.

595 Alternatively, the life history problem outlined in our model could be solved using 596 evolutionary modelling techniques that work also under density dependence. Adaptive 597 dynamics is such a technique (Dieckmann and Law 1996). In practice, making assumptions 598 about how an evolutionary change in one allocation value would incur correlated changes also 599 in other values is exceedingly difficult for more than two or a few traits (compared to the 6.4 600 million values in our model). With this, adaptive dynamics often got stuck in local optima that

601 prevented further evolution (C. Jørgensen, B. Ernande and U. Dieckmann, pers. obs.). A 602 second alternative is simulations of evolving population using genetic algorithms and 603 artificial neural networks to approximate the allocation hypersurface (Huse et al. 1999). These 604 models are, however, hard to trace: it is hard to ascertain when the neural network formulation 605 allows sufficient detail in the allocation hypersurface, and whether globally optimal solutions 606 are indeed found or not. We feel these uncertainties would be harder to accept than any 
607 potential effects of density dependence, partly also because there is a weak tradition for 608 including density dependence in models.

609 In conclusion, there is a promising agreement between field data and the model prediction

610 of growth and maturation. In addition, the model gives a very realistic appearance of

611 reproduction and other ecological interactions. Modelling tools such as this one can therefore

612 be used for large-scale experiments that are logistically impossible or awkward in the field or

613 lab. Because the entire population - structured by age, size and stored energy - is available

614 throughout the stochastic simulation of population dynamics, a large array of various data can

615 be explored in a more experiment-like way (Peck 2004). For instance, the model can be used

616 to study effects of increased fishery mortalities: is the increasing mortality imposed by

617 fisheries sufficient to induce life history evolution (e.g., Law and Grey 1989; Heino 1998;

618 Olsen et al. 2004)? Another example, to which this model has already been applied, is skipped

619 reproduction in fish (Jørgensen et al. this issue). The life history model suggests that the

620 counter-intuitive phenomenon of skipped spawning may be more common than previously

621 believed, and gives us the opportunity to study the underlying logic. The model provides a

622 tool for large-scale investigations of the life history of cod in different ecological settings.

623 Life history models, such as the one presented here, is a powerful tool for investigating both

624 driving forces behind instantiated life history strategies, as well as assessing and predicting

625 potential changes derived from altered external forcing such as fisheries and climate change.

\section{Acknowledgements}

627 Thanks go to Ken Andersen, Ulf Dieckmann, Bruno Ernande, Jarl Giske, Mikko Heino, 628 Marc Mangel, Tara Marshall, and Espen Strand for valuable comments and input. Jørgensen 629 was funded by the Research Council of Norway. 


\section{References}

631 Alexander, R.M. 2003. Principles of animal locomotion. Princeton University Press,

$632 \quad$ Princeton and Oxford.

633 Brander, K. 1994. Spawning and life history information for North Atlantic cod stocks.

634 International Council for the Exploration of the Sea, Copenhagen, Denmark.

635 Burton, M.P.M., Penney, R.M., and Biddiscombe, S. 1997. Time course of gametogenesis in

636 Northwest Atlantic cod (Gadus morhua). Can. J. Fish. Aquat. Sci., 54 (Suppl. 1): 122-131.

637 Clark, C.W. and Mangel, M. 2000. Dynamic state variable models in ecology. Oxford

638 University Press, New York.

639 Conover, D.O. and Munch, S.B. 2002. Sustaining fisheries yields over evolutionary time

$640 \quad$ scales. Science, 297: 94-96.

641 Dieckmann, U. and Law, R. 1996. The dynamical theory of coevolution: a derivation from

642 stochastic ecological processes. J. Math. Biol., 34: 579-612.

643 Dutil, J.D. and Lambert, Y. 2000. Natural mortality from poor condition in Atlantic cod

644 (Gadus morhua). Can. J. Fish. Aquat. Sci., 57: 826-836.

645 Fisher, R.A. 1930. Genetical theory of natural selection. Oxford University Press, Oxford, $646 \quad$ UK.

647 Fordham, S.E. and Trippel, E.A. 1999. Feeding behaviour of cod (Gadus morhua) in relation 648 to spawning. J. Appl. Ichthyol., 15: 1-9.

649 Hansson, S., Rudstam, L.G., Kitchell, J.F., Hilden, M., Johnson, B.L., and Peppard, P.E. 650 1996. Predation rates by North Sea cod (Gadus morhua) - predictions from models on 651 gastric evacuation and bioenergetics. ICES J. Mar. Sci., 53: 107-114.

652 Heino, M. 1998. Management of evolving fish stocks. Can. J. Fish. Aquat. Sci., 55: 1971653 1982. 
654 Heino, M., Dieckmann, U., and Godø, O.R. 2002. Measuring probabilistic reaction norms for 655 age and size at maturation. Evolution, 56: 669-678.

656 Heino, M. and Kaitala, V. 1996. Optimal resource allocation between growth and reproduction in clams: why does indeterminate growth exist? Funct. Ecol., 10: 245-251.

Helle, K., Pennington, M., Bogstad, B., and Ottersen, G. 2002. Early environmental influences on growth of Arcto-Norwegian cod, Gadus morhua, from the 0-group to adults. $660 \quad$ Environ. Biol. Fish., 65: 341-348.

661 Hewett, S.W. and Johnson, B.L. 1992. Fish bioenergetics model 2. University of Wisconsin, 662 Sea Grant Institute, Madison, Wisconsin.

663 Holdway, D.A. and Beamish, F.W.H. 1984. Specific growth rate and proximate body 664 composition of Atlantic cod (Gadus morhua L.). J. Exp. Mar. Biol. Ecol., 81: 147-170. 665 Houston, A.I. and McNamara, J.M. 1999. Models of adaptive behaviour: an approach based 666 on state. Cambridge University Press, Cambridge, UK.

667 Huse, G., Strand, E., and Giske, J. 1999. Implementing behaviour in individual-based models 668 using neural networks and genetic algorithms. Evol. Ecol., 13: 469-483.

669 ICES. 2003. Report of the Arctic fisheries working group. ICES Advisory Committee on 670 Fishery Management, ICES CM 2003/ACFM:22.

671 Jobling, M. 1988. A review of the physiological and nutritional energetics of cod, Gadus 672 morhua L, with particular reference to growth under farmed conditions. Aquaculture, 70: $673 \quad 1-19$.

674 Jørgensen, C., Ernande, B., Fiksen, Ø., and Dieckmann, U. This issue. The logic of skipped 675 spawning in fish. Can. J. Fish. Aquat. Sci.

676 Jørgensen, T. 1992. Long-term changes in growth of North-east Arctic cod (Gadus morhua) 677 and some environmental influences. ICES J. Mar. Sci., 49: 263-277. 
Kjesbu, O.S., Klungsøyr, J., Kryvi, H., Witthames, P.R., and Walker, M.G. 1991. Fecundity, atresia, and egg size of captive Atlantic cod (Gadus morhua) in relation to proximate body composition. Can. J. Fish. Aquat. Sci., 48: 2333-2343.

681 Kjesbu, O.S., Solemdal, P., Bratland, P., and Fonn, M. 1996. Variation in annual egg production in individual captive Atlantic cod (Gadus morhua). Can. J. Fish. Aquat. Sci., 53: $610-620$.

Kozlowski, J. and Teriokhin, A.T. 1999. Allocation of energy between growth and reproduction: the Pontryagin maximum principle solution for the case of age- and seasondependent mortality. Evol. Ecol. Res., 1: 423-441.

Krebs, J.R. and Davies, N.B. 1993. En introduction to behavioural ecology, 3rd edn. Blackwell Scientific Publications, Oxford, UK.

Lambert, Y. and Dutil, J.D. 1997. Can simple condition indices be used to monitor and quantify seasonal changes in the energy reserves of Atlantic cod (Gadus morhua)? Can. J. Fish. Aquat. Sci., 54, Suppl. 1: 104-112.

Lambert, Y. and Dutil, J.D. 2000. Energetic consequences of reproduction in Atlantic cod (Gadus morhua) in relation to spawning level of somatic energy reserves. Can. J. Fish. Aquat. Sci., 57: 815-825.

Law, R. and Grey, D.R. 1989. Evolution of yields from populations with age-specific cropping. Evol. Ecol., 3: 343-359.

697 Marshall, C.T., Kjesbu, O.S., Yaragina, N.A., Solemdal, P., and Ulltang, Ø. 1998. Is spawner 698 biomass a sensitive measure of the reproductive and recruitment potential of Northeast 699 Arctic cod? Can. J. Fish. Aquat. Sci., 55: 1766-1783.

700 Marshall, C.T., Yaragina, N.A., Lambert, Y., and Kjesbu, O.S. 1999. Total lipid energy as a 701 proxy for total egg production by fish stocks. Nature, 402: 288-290. 
McNamara, J.M., Webb, J.N., Collins, E.J., Szekely, T., and Houston, A.I. 1997. A general

703 technique for computing evolutionarily stable strategies based on errors in decision-

704 making. J. Theor. Biol., 189: 211-225.

705 Michalsen, K., Ottersen, G., and Nakken, O. 1998. Growth of North-east Arctic cod (Gadus

706 morhua L.) in relation to ambient temperature. ICES J. Mar. Sci., 55: 863-877.

707 Mylius, S.D. and Diekmann, O. 1995. On evolutionarily stable life histories, optimization and 708 the need to be specific about density dependence. Oikos, 74: 218-224.

709 Nøttestad, L., Giske, J., Holst, J.C., and Huse, G. 1999. A length-based hypothesis for feeding 710 migrations in pelagic fish. Can. J. Fish. Aquat. Sci., 56, Suppl. 1: 26-34.

711 Olsen, E.M., Heino, M., Lilly, G.R., Morgan, M.J., Brattey, J., Ernande, B., and Dieckmann,

712 U. 2004. Maturation trends indicative of rapid evolution preceded the collapse of northern 713 cod. Nature, 428: 932-935.

714 Ona, E. 1990. Physiological factors causing natural variations in acoustic target strength of

715 fish. J. Mar. Biol. Assoc. UK, 70: 107-127.

716 Peck, S.L. 2004. Simulation as experiment: a philosophical reassessment for biological

717 modeling. Trends Ecol. Evol., 19: 530-534.

718 Roff, D.A. 1983. An allocation model of growth and reproduction in fish. Can. J. Fish. Aquat. 719 Sci., 40: 1395-1404.

720 Schmidt-Nielsen, K. 1984. Scaling. Why is animal size so important? Cambridge University 721 Press, Cambridge, UK.

722 Stearns, S.C. and Koella, J.C. 1986. The evolution of phenotypic plasticity in life-history 723 traits: predictions of reaction norms for age and size at maturity. Evolution, 40: 893-913.

724 Stokes, K. and Law, R. 2000. Fishing as an evolutionary force. Mar. Ecol.-Progr. Ser., 208: 725 307-309. 
726 Strand, E., Huse, G., and Giske, J. 2002. Artificial evolution of life history and behavior. Am.

727 Nat., 159: 624-644.

728 Strand, E., Jørgensen, C., and Huse, G. 2005. Modelling buoyancy regulation in fishes with

729 swimbladders: bioenergetics and behaviour. Ecol. Model., 185: 309-327.

730 Sutherland, W.J. 2005. The best solution. Nature, 435: 569.

731 Svåsand, T., Jørstad, K.E., Otterå, H., and Kjesbu, O.S. 1996. Differences in growth

732 performance between Arcto-Norwegian and Norwegian coastal cod reared under identical

733 conditions. J. Fish Biol., 49: 108-119.

734 Taborsky, B., Dieckmann, U., and Heino, M. 2003. Unexpected discontinuities in life-history

735 evolution under size-dependent mortality. Proc. R. Soc. Lond. B, 270: 713-721.

736 Tyler, C.R. and Sumpter, J.P. 1996. Oocyte growth and development in teleosts. Rev. Fish

737 Biol. Fish., 6: 287-318.

738 Ware, D.M. 1978. Bioenergetics of pelagic fish: theoretical change in swimming speed and

739 ration with body size. J. Fish. Res. Bd. Can., 35: 220-228.

740 Yaragina, N.A. and Marshall, C.T. 2000. Trophic influences on interannual and seasonal

741 variation in the liver condition index of Northeast Arctic cod (Gadus morhua). ICES J.

$742 \quad$ Mar. Sci., 57: 42-55. 


\section{Appendix 1}

\section{Justification for choice of minimum and maximum condition factors}

745 Growth in the model was sensitive to the choice of minimum and maximum condition

746 factors. The following reasons for choosing $K_{\min }$ and $K_{\max }$ were therefore tightly coupled with

747 sensitivity tests and comparisons with growth data. In an experiment following individual cod

748 throughout the spawning season (length $56-87 \mathrm{~cm}$; only females considered here), mean pre-

749 spawning condition factor was 1.39 (range 1.19-1.75), while the average for spent cod was

$750 \quad 0.97$ (range 0.81-1.13) (Fordham and Trippel 1999). Using these condition factors for $K_{\min }$

751 and $K_{\max }$ in the model, however, gives higher condition factors and weight-at-age than is

752 observed for the Northeast Arctic cod stock. This can be partly because eggs swell prior to

753 spawning by taking up water (Tyler and Sumpter 1996; Fordham and Trippel 1999), which

754 may artificially inflate condition factors for pre-spawning cod so that they no longer reflect

755 the true size of energy stores. The extent of water uptake can be illustrated by the fact that

756 total volume of eggs spawned was on average $150 \%$ of post-spawning body volume in the

757 same study (Fordham and Trippel 1999). Also, cod were fed ad libitum throughout the

758 spawning period in that study, and the easy access to food compared to natural conditions

759 may have improved final condition. A somewhat lower maximum value, $K_{\max }=1.25$, was

760 therefore selected. In a starvation experiment, cod died when condition factors reached 0.44

761 (range 0.36-0.56; length 31-55 cm), although liver energy stores were depleted before this

762 (Dutil and Lambert 2000). The $K_{\min }$ in this model should, however, reflect the condition at

763 which routine energy stores are depleted, not the level to which severe food stress can atrophy

764 muscle mass before death occurs. A value of $K_{\min }=0.75$ was therefore chosen through

765 thorough testing since it reproduced appropriate weight-at-length compared to field data (e.g.

766 Fig. 4.). Conditions factors in the model are given relative to a standard length $L_{\text {std }}=70 \mathrm{~cm}$, 
767 which means that realised $K_{\min }$ is in the range 0.71-0.74 for the lengths used in Dutil and 768 Lambert (2000). 
Table 1. Parameters used for Northeast Arctic cod (Gadus morhua) in a model for statedependent energy allocation.

\begin{tabular}{|c|c|c|}
\hline $\begin{array}{l}\text { Para- } \\
\text { meter }\end{array}$ & Value and unit & Biological interpretation \\
\hline$\varepsilon$ & 0.065 & $\begin{array}{l}\text { Value of coefficient above } 3 \text { for allometric scaling } \\
\text { between body mass and length }\end{array}$ \\
\hline$K_{\min }$ & $0.75 \mathrm{~g} \cdot \mathrm{cm}^{-3}$ & Minimum condition factor at standard length $L_{\text {std }}$ \\
\hline$K_{\max }$ & $1.25 \mathrm{~g} \cdot \mathrm{cm}^{-3}$ & Maximum condition factor at standard length $L_{\text {std }}$ \\
\hline$L_{\text {std }}$ & $70 \mathrm{~cm}$ & Length for which $K_{\min }$ and $K_{\max }$ are defined \\
\hline$\rho_{\mathrm{E}}$ & $8700 \mathrm{~J} \cdot \mathrm{g}^{-1}$ & Energy density of muscle and liver energy stores \\
\hline$\rho_{\mathrm{S}}$ & $4000 \mathrm{~J} \cdot \mathrm{g}^{-1}$ & Energy density of somatic tissue \\
\hline$A_{c t}$ & 1.25 & Proportional increase in metabolic rate due to activity \\
\hline$\kappa_{1}$ & $\begin{array}{c}1693 \\
\mathrm{~J} \cdot \mathrm{g}^{-\beta_{1}} \cdot \mathrm{month}^{-1}\end{array}$ & Coefficient of allometric metabolic function \\
\hline$\beta_{1}$ & 0.828 & Exponent of allometric metabolic function \\
\hline$\kappa_{2}$ & $\begin{array}{c}276 \\
\mathrm{~J} \cdot \mathrm{cm}^{-\beta_{2}} \cdot \mathrm{month}^{-1}\end{array}$ & Coefficient of allometric feeding function (of length) \\
\hline$\beta_{2}$ & 2.408 & Exponent of allometric feeding function (of length) \\
\hline $\bar{\chi}$ & 0.75 & Mean food intake relative to feeding function \\
\hline$C_{1}$ & 0.9 & $\begin{array}{l}\text { Auto-correlation coefficient for environmental } \\
\text { stochasticity }\end{array}$ \\
\hline$C_{2}$ & 0.15 & Scaling of environmental stochasticity \\
\hline$\Delta L_{\max }$ & $18 \mathrm{~cm} \cdot$ year $^{-1}$ & Maximum growth rate \\
\hline$D_{\mathrm{M}}$ & $7.8 \cdot 10^{5} \mathrm{~m}$ & Distance for spawning migration \\
\hline
\end{tabular}




\begin{tabular}{|c|c|c|}
\hline$U_{\mathrm{S}}$ & $0.3 \mathrm{~m} \cdot \mathrm{s}^{-1}$ & Swimming speed during spawning migration \\
\hline$U_{\mathrm{C}}$ & $0.1 \mathrm{~m} \cdot \mathrm{s}^{-1}$ & $\begin{array}{l}\text { Speed of northwards current during spawning } \\
\text { migration }\end{array}$ \\
\hline$\kappa_{4}$ & $320 \mathrm{~cm} \cdot \mathrm{s}^{1.5} \cdot \mathrm{m}^{-1.5}$ & Coefficient for empirical cost of swimming function \\
\hline$P_{\text {lipids }}$ & 0.63 & Proportion of total energy stored as lipids in liver \\
\hline$L C I_{\max }$ & $9 \%$ & Maximum weight of liver relative to body weight \\
\hline$\delta_{\text {store }}$ & 0.4 & Efficiency of storing ingested energy \\
\hline$\delta_{\text {growth }}$ & 0.08 & $\begin{array}{l}\text { Efficiency of building somatic body mass from } \\
\text { ingested energy }\end{array}$ \\
\hline$\kappa_{5}$ & $0.256 \mathrm{eggs} \cdot \mathrm{J}^{-1}$ & Conversion between stored energy and spawned eggs \\
\hline$M$ & 0.25 year $^{-1}$ & Natural mortality \\
\hline$M_{\mathrm{S}}$ & 0.1 year $^{-1}$ & Increased mortality during spawning and migration \\
\hline$F_{\mathrm{F}}$ & 0.20 year $^{-1}$ & Feeder fisheries mortality \\
\hline$F_{\mathrm{S}}$ & 0.22 year $^{-1}$ & Spawner fisheries mortality \\
\hline$a_{\max }$ & 25 years & Maximum age \\
\hline$a_{\min }$ & 2 years & Age at which recruits are introduced in the model \\
\hline$L_{\text {min }}$ & $25 \mathrm{~cm}$ & Length of recruits \\
\hline
\end{tabular}




\section{Figure captions}

772

773

774

775

776

777

778

779

780

781

782

783

784

785

786

787

788

789

790

791

792

793

794

795

Figure 1. Schematic overview over a life-history energy allocation model for the Northeast Arctic cod (Gadus morhua). Energy allocation and the states influencing it are shaded in grey. Black arrows indicate energy flow. The dotted line indicates that energy stores are drained in periods when food intake cannot sustain metabolic demands.

Figure 2. Predicted length and weight at age from a life history model for the Northeast Arctic cod (Gadus morhua) compared to field data. Grey points are data from the Barents Sea (mostly immature fish), while black open circles are from the Lofoten area (mostly mature fish). (a) Length (cm) at age (years). (b) Weight (kg) at age (years).

Figure 3. Maturity ogives from a life history model for the Northeast Arctic stock of Atlantic cod (Gadus morhua). (a) Proportion mature as a function of body length in $\mathrm{cm}$. The equation for the logistic regression is $y=1 /[1+\exp (-0.45 \cdot(x-77.6))]$. (b) Proportion mature as a function of age in years (black circles). Grey squares are field data for the Northeast Arctic cod stock for comparison (from ICES 2003). The equation for the logistic regression is $\mathrm{y}=1 /[1+\exp (-1.7 \cdot(\mathrm{x}-7.5))]$

Figure 4. Growth trajectory and physiology for one individual female cod from a life history model for the Northeast Arctic cod Gadus morhua, simulated in a stochastic environment. The $x$-axis shows age and is common for all the graphs. Only one individual's life trajectory is shown in this figure. A population of individuals, each with a corresponding life trajectory, was simulated for the remaining results in this paper. This individual diverted energy towards stores at age 7, approximately one year prior to first spawning to prepare for sexual maturation. (a) Length (black line, left axis) and weight (grey line, right axis). (b) Allocation of available energy between energy stores (1) and growth (0). The line shows gaps because no energy is available for allocation during spawning migrations. (c) Fulton's condition factor (black line). The grey lines represent minimum and maximum condition 
factors attainable at that length; these increase because body mass is proportional to length to the power of 3.065. (d) Number of eggs spawned (in millions). (e) Food availability in the stochastic environment measured relative to the mean. (f) Probability of survival until age

799 (note the logarithmic $y$-axis).

Figure 5. Fecundity in relation to various individual characteristics. The $y$-axis is common

801 for all graphs and show fecundity in million eggs. The results are from population simulation in a stochastic environment for 1000 years. (a) Fecundity vs. age (years). (b) Fecundity vs.

803 body mass (kg). (c) Fecundity vs. body length (cm). (d) Fecundity vs. liver weight (g).

804 Figure 6. Comparison of population-level predictors of total egg production in the 805 population. The $y$-axis is common for all the plots and shows the total egg production in the 806 population. All axes are normalised to the mean, and the results are from population 807 simulation in a stochastic environment for 1000 years. Coefficients of variation $r^{2}$ are given 808 for linear regressions on each data set. (a) Biomass of all sexually mature individuals 809 (individuals that do not spawn but that have spawned previously are included) $\left(r^{2}=0.897\right)$.

810 (b) Biomass of spawners only $\left(r^{2}=0.995\right)$. (c) Total liver weight of all sexually mature 811 individuals (individuals that do not spawn but have spawned previously are included) $812 \quad\left(r^{2}=0.986\right) .(d)$ Total liver weight of spawners only $\left(r^{2}=0.998\right)$.

813 Figure 7. The influence of mean food availability on population characteristics in January 814 (just before spawning season) in a life history model for the Northeast Arctic cod. All axes 815 show values relative to the mean. Each point represents one year from 1000 years simulation 816 of population dynamics. (a) In general, mature biomass was higher when mean food 817 availability last two years was higher. Mature biomass includes effects of increased numbers 818 of fish, increased proportion of mature fish, and increased condition. (b) Total egg production 819 for the stock also showed a tendency to increase with increasing food availability. 


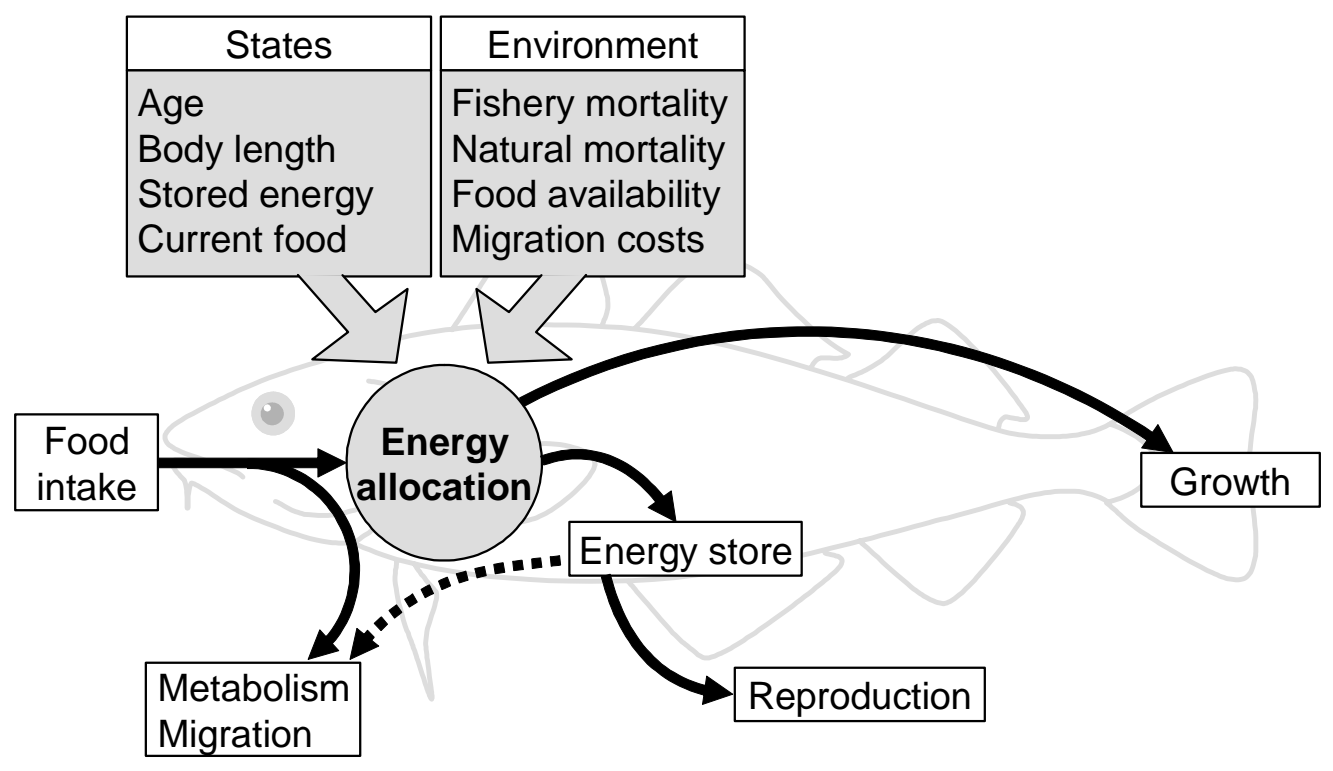


821 Jørgensen and Fiksen. State-dependent energy allocation in cod (Gadus morhua)

822 Figure 1 


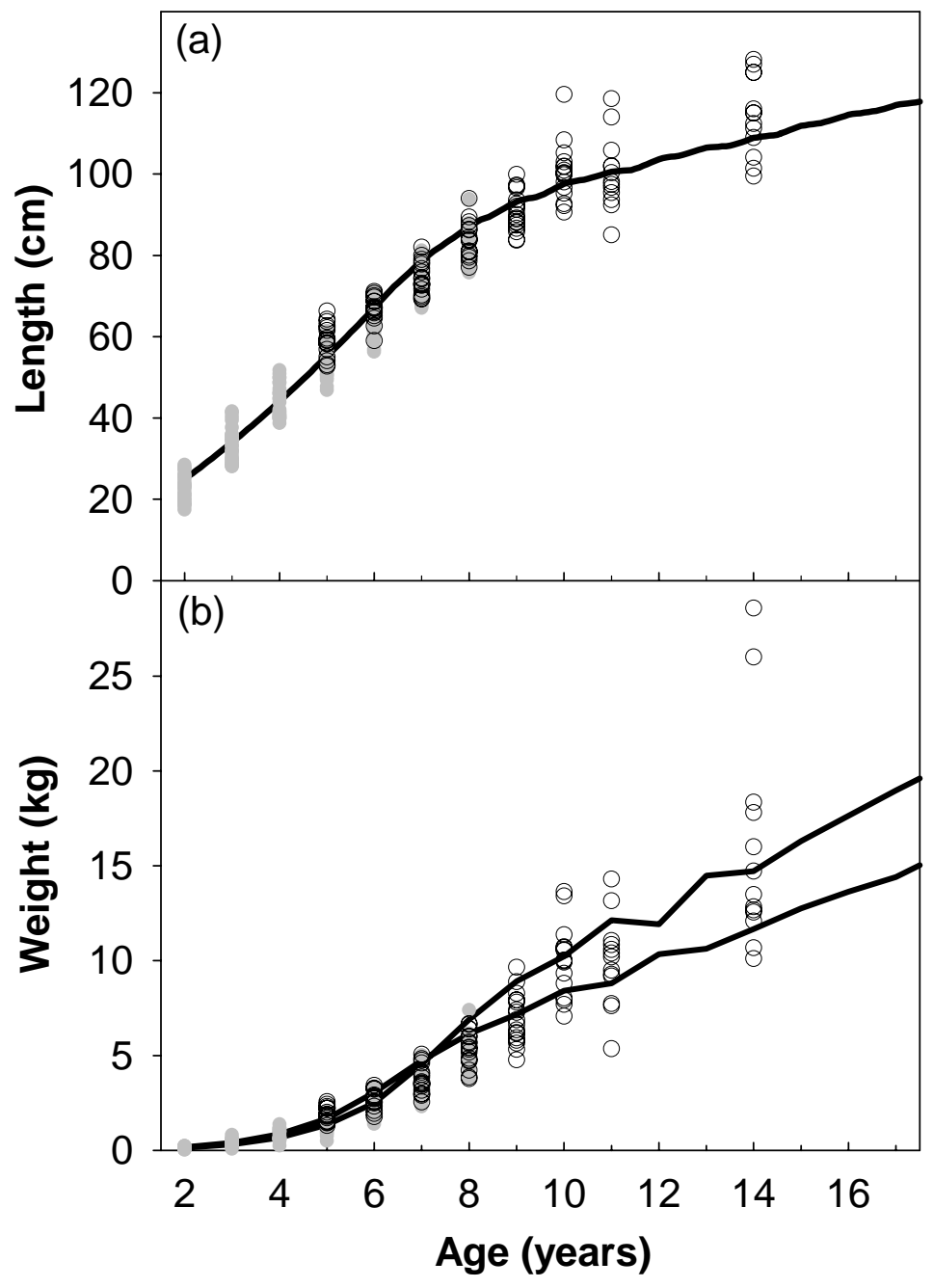

823 Age (years) 
824 Jørgensen and Fiksen. State-dependent energy allocation in cod (Gadus morhua)

$825 \quad$ Figure 2 

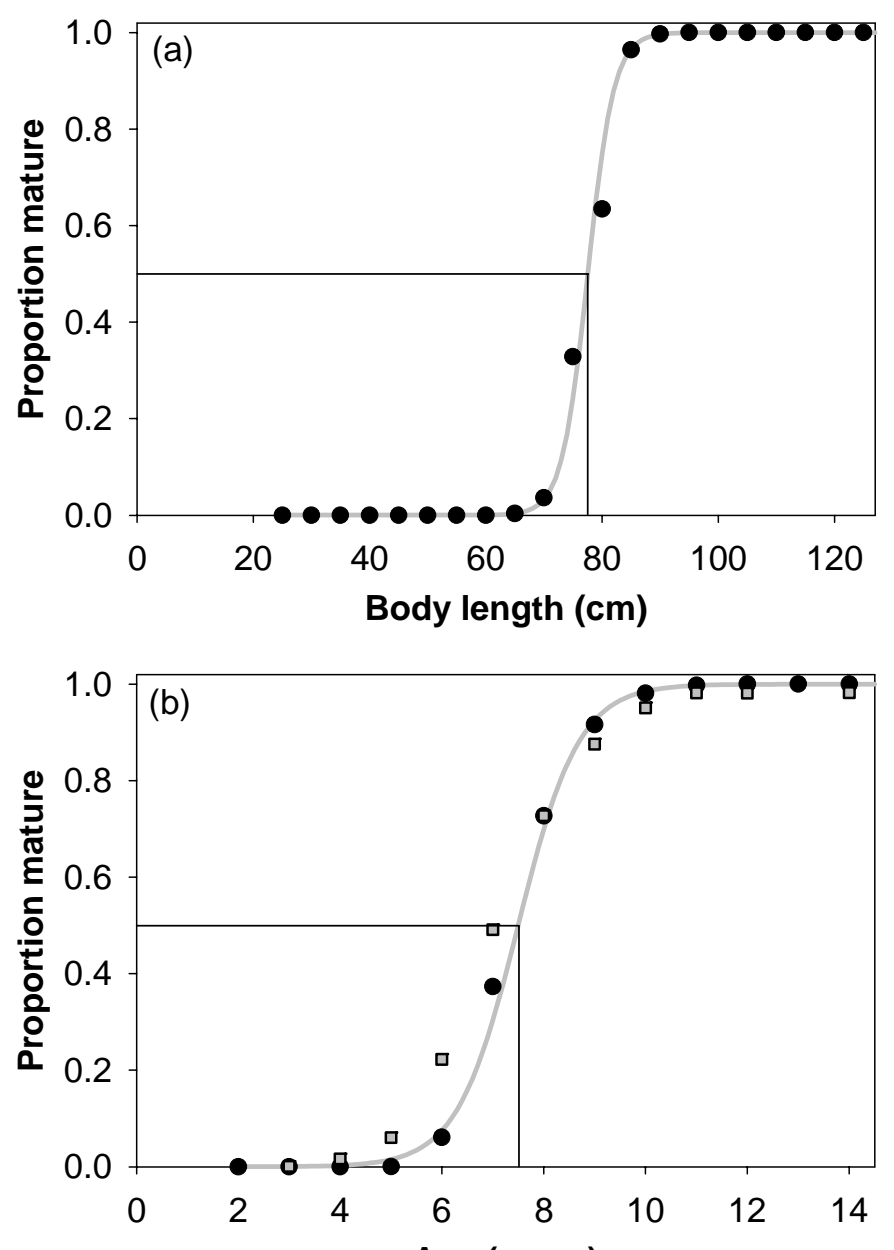

826 Age (years) 
827 Jørgensen and Fiksen. State-dependent energy allocation in cod (Gadus morhua)

828 Figure 3 

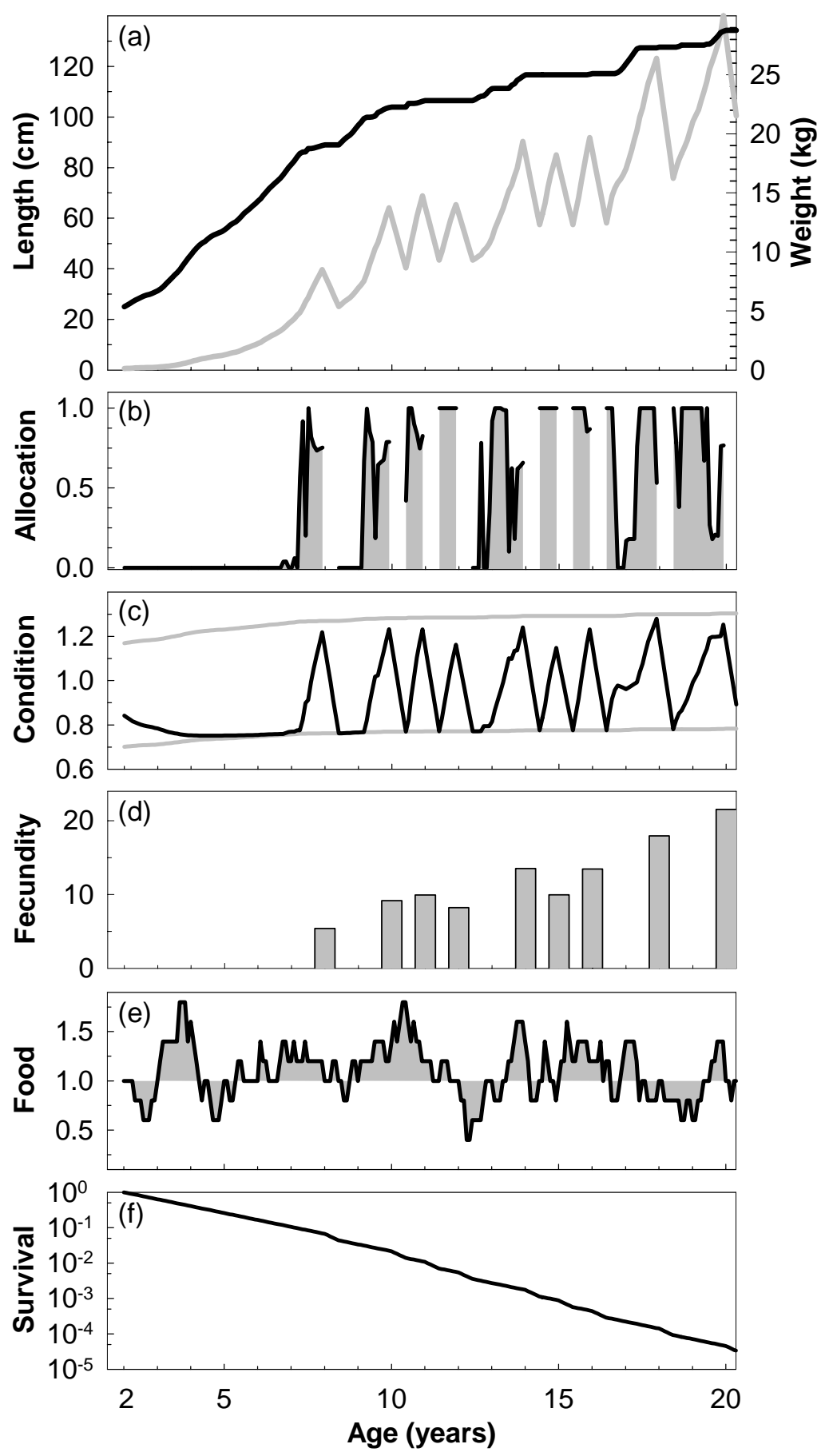

829

Age (years) 
830 Jørgensen and Fiksen. State-dependent energy allocation in cod (Gadus morhua)

$831 \quad$ Figure 4 

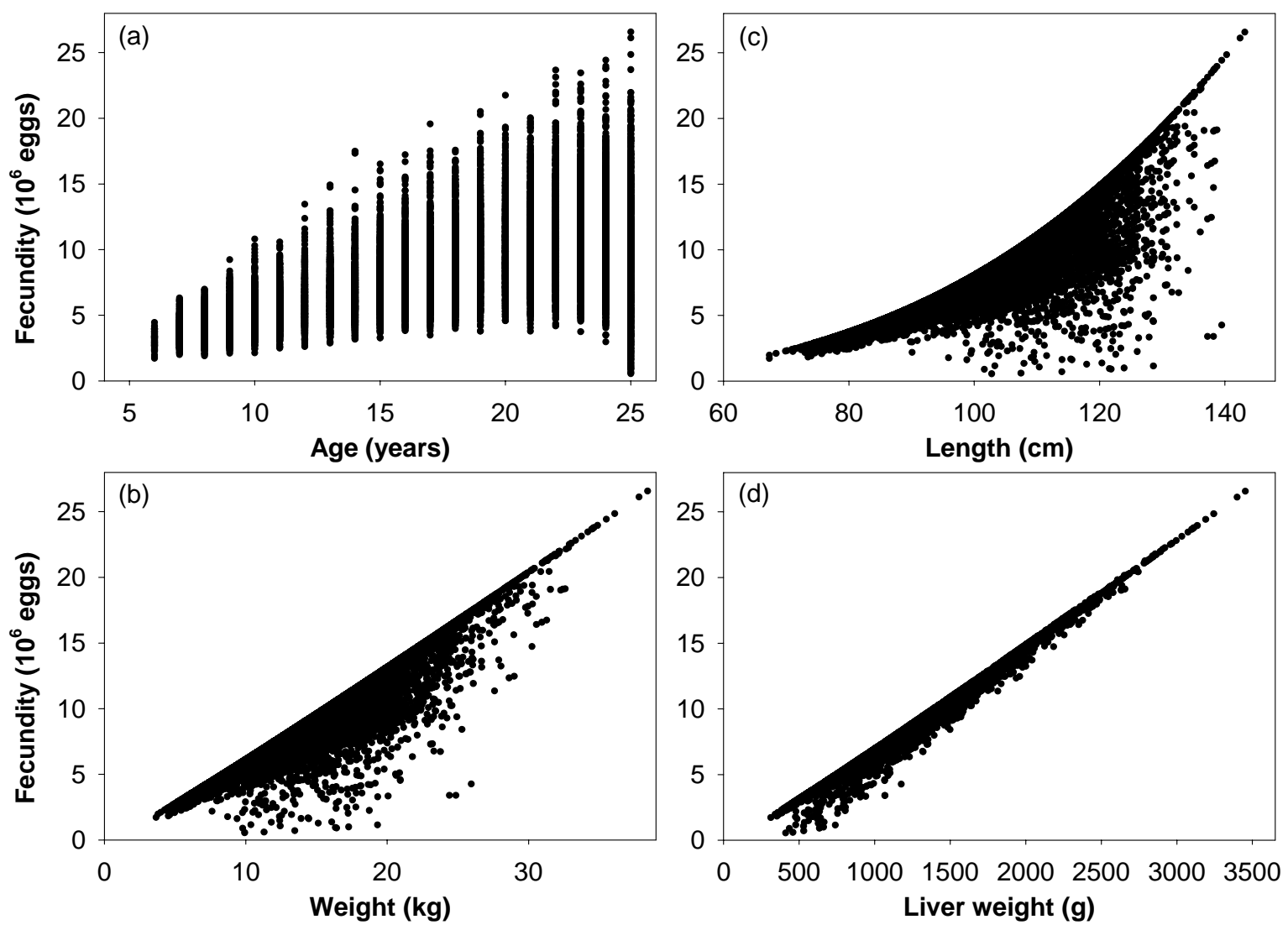
833 Jørgensen and Fiksen. State-dependent energy allocation in cod (Gadus morhua)

$834 \quad$ Figure 5 

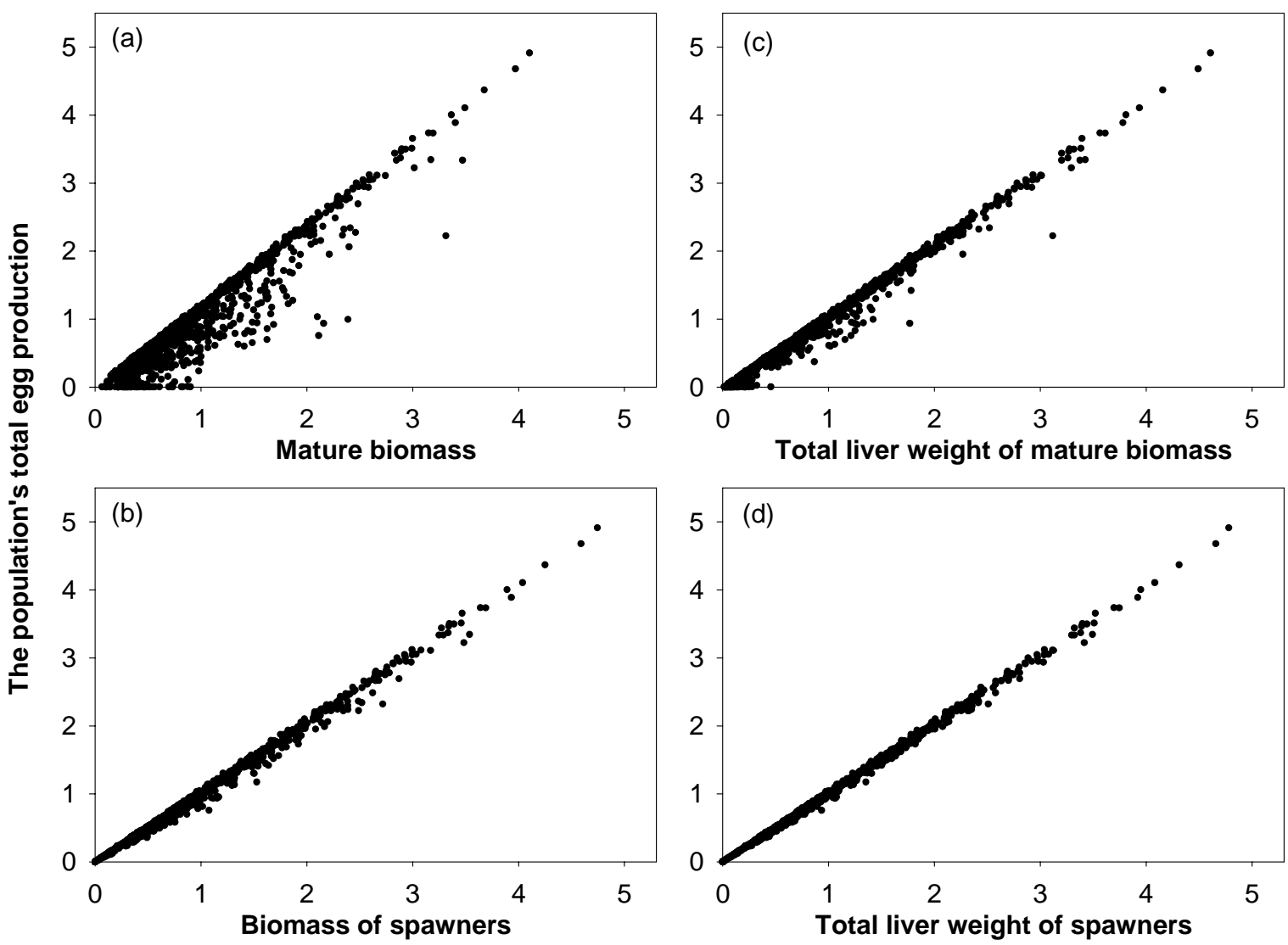
836 Jørgensen and Fiksen. State-dependent energy allocation in cod (Gadus morhua)
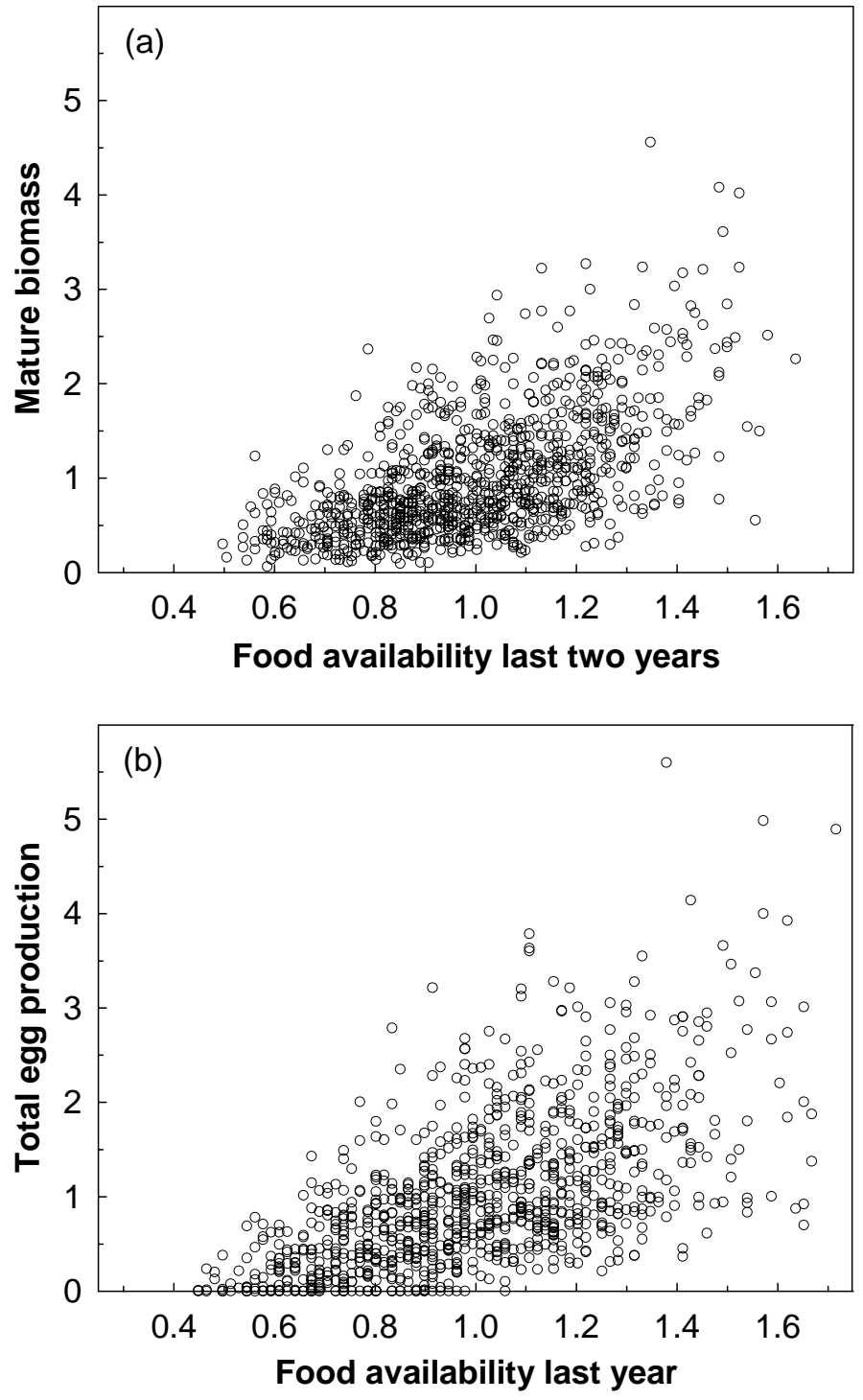
839 Jørgensen and Fiksen. State-dependent energy allocation in cod (Gadus morhua)

Figure 7 